\title{
Recycling carbon fibre reinforced polymers for structural applications: technology review and market outlook
}

\author{
Soraia Pimenta*, Silvestre T. Pinho \\ The Composites Centre, Department of Aeronautics, South Kensington Campus, Imperial College \\ London. London SW7 2AZ, United Kingdom
}

\begin{abstract}
Both environmental and economic factors have driven the development of recycling routes for the increasing amount of carbon fibre reinforced polymer (CFRP) waste generated. This paper presents a review of the current status and outlook of CFRP recycling operations, focusing on state-of-the-art fibre reclamation and re-manufacturing processes, and on the commercialisation and potential applications of recycled products. It is shown that several recycling and re-manufacturing processes are reaching a mature stage, with implementations at commercial scales in operation, production of recycled CFRPs having competitive structural performances, and demonstrator components having been manufactured. The major challenges for the sound establishment of a CFRP recycling industry and the development of markets for the recyclates are summarised; the potential for introducing recycled CFRPs in structural components is discussed, and likely promising applications are investigated.
\end{abstract}

Keywords: Carbon fibre reinforced polymers, Recycling, Fibre reclamation, Manufacturing Structural applications,

\section{Introduction}

The increasing use of carbon fibre reinforced polymers (CFRPs) has raised an environmental and economic awareness for the need to recycle the CFRP waste. The latest governmental UK strategy for composites (BIS 2009) identifies "Increasing Sustainability and Recycling" as one of the three major goals for the composites industry. In this paper, the current status of recycling processes for CFRP and the forthcoming challenges for the introduction of the recyclates in structural applications are reviewed.

The world-wide demand for carbon fibres (CFs) reached approximately 35, $000 \mathrm{t}$ in 2008; this number is expected to double by 2014, representing a growth rate of over $12 \%$ per year (Roberts 2009). CFRP is now used in a widening range of applications, and in growing content in most of them (Sloan 2008); the aircraft industry is an impressive

${ }^{*}$ Corresponding author.

Email address: soraia.pimenta@imperial.ac.uk (Soraia Pimenta)

Pimenta S, Pinho ST (2011). Recycling carbon fibre reinforced polymers for structural applications: technology review and market outlook. Waste Management 31, 378-392. DOI : $10.1016 / j$. wasman. 2010.09.019 


\begin{tabular}{|llll|}
\hline \multicolumn{2}{|c|}{ Variables } & Nomenclature & \\
$E$ & Young's modulus & Superscripts \\
$G_{\mathrm{c}}$ & fracture toughness & $\mathrm{f}$ fibre \\
$l$ & length & \multicolumn{2}{|c|}{ Subscripts } \\
$S$ & shear strength & avg average \\
$U$ & energy absorption & $\mathrm{IF}$ interfacial \\
$V$ & volume fraction & $\mathrm{imp}$ impact \\
$X$ & uniaxial strength & $\mathrm{T}$ & tensile \\
\hline
\end{tabular}

example, with the new Boeing 787 and Airbus A350 having up to 50\% of their weight in CFRP, and military aircraft showing a similar trend (Marsh 2008).

Despite all advantages associated with CFRPs, the increasing use generates an also increasing amount of CFRP waste. Common sources of waste include out-of-date prepregs, manufacturing cut-offs, testing materials, production tools and end-of-life (EoL) components (Figure 1); manufacturing waste is approximately $40 \%$ of all the CFRP waste generated (Pickering et al. 2006), while woven trimmings contribute with more than $60 \%$ to this number (Hunter 2009). Continuing with the aeronautics sector as example, the first aircraft with structural CFRP components will soon be decommissioned (Marsh 2008); within 30 years, the same will happen to the new composite-generation aircraft (8,500 commercial planes will be retired by 2025, Carberry 2008), with each vehicle representing more than 20 t of CFRP waste (Roberts 2007). Within a similar time frame, the wind industry will be another great source of CFRP waste (Wood 2010).

Recycling composites is inherently difficult because of (i) their complex composition (fibres, matrix and fillers), (ii) the cross-linked nature of thermoset resins (which cannot be remoulded), and (iii) the combination with other materials (metal fixings, honeycombs, hybrid composites, etc.). Presently, most of the CFRP waste is landfilled (Pickering 2006); the airframe of EoL vehicles is usually disposed in desert graveyards, airports, or by landfilling (Carberry 2008, PAMELA 2005). However, these are unsatisfactory solutions for several reasons:

- Environmental impact: the increasing amount of CFRP produced raises concerns on waste disposal and consumption of non-renewable resources.

- Legislation: recent European legislation is enforcing a strict control of composite disposal; the responsibility of disposing EoL composites is now on the component's manufacturer, legal landfilling of CFRP is limited, and for instance it is required that automotive vehicles disposed after 2015 are 85\% recyclable (EU 1999/31/EC 1999, EU 2000/53/EC 2000).

- Production cost: CFs are expensive products, both in terms of energy consumed during manufacturing (up to $165 \mathrm{kWh} / \mathrm{kg}$ ) and material price (up to $40 £ / \mathrm{kg}$ ) (Carberry 2008). 


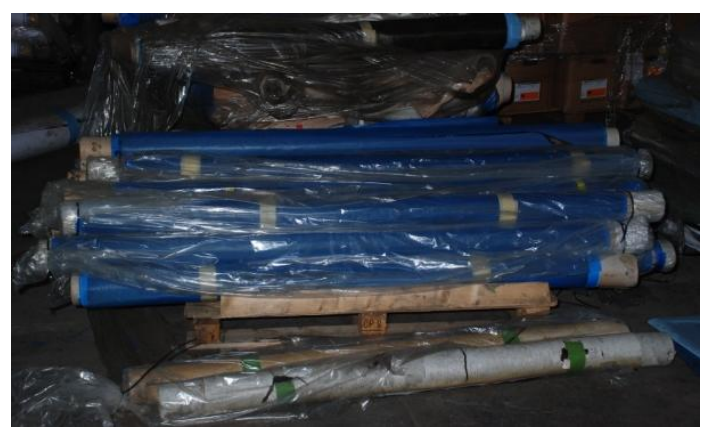

(a) Out-of-date prepreg rolls.

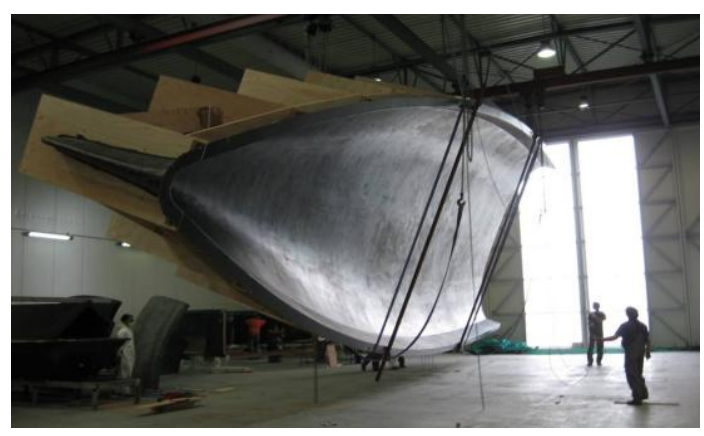

(c) Yatch mould.

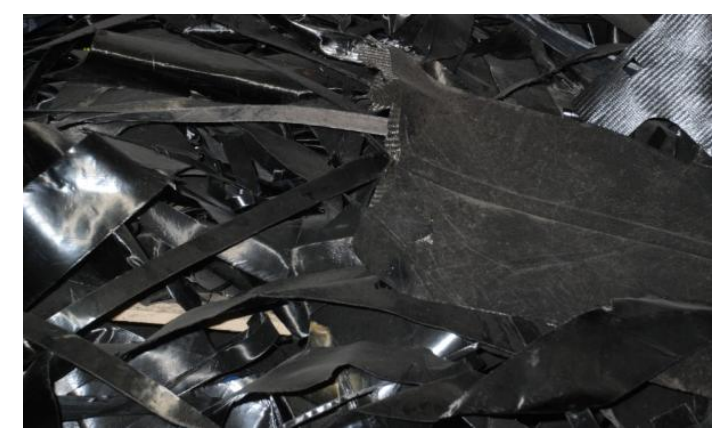

(b) Manufacturing cut-offs.

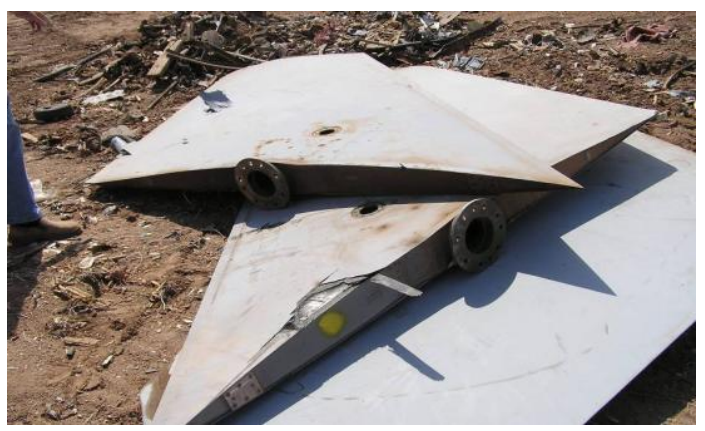

(d) EoL-aircraft wings.

Figure 1: CFRP waste (Panesar 2009).

- Management of resources: demand of virgin (v-) CFs usually surpasses supplycapacity (Roberts 2007), so recycled (r-) CFs could be re-introduced in the market for non-critical applications (Carberry 2009).

- Economic opportunity: disposing of CFRP by landfilling, where not illegal, can cost approximately $0.20 £ / \mathrm{kg}$ (Meyer et al. 2007); recycling would convert an expensive waste disposal into a profitable reusable material.

It is clear that turning CFRP waste into a valuable resource and closing the loop in the CFRP life-cycle (Figure 2) is vital for the continued use of the material in some applications, e.g. the automotive industry (Pickering 2006). This need has driven not only a great amount of research on recycling processes for CFRPs over the last 15 years, but also the formation of several collaborative entities working on a more commercial or industrial level (Table 1).

Some review papers on carbon-fibre recycling are available in the literature; DeRosa et al. (2005) and Pickering (2006) focused on established recycling processes, while McConnel (2010) and Wood (2010) discussed their implementation at commercial scales. However, there is a strong connection between recycling, re-manufacturing processes and the final performance of the recyclates (Pimenta et al. 2010a); this clearly affects the type of markets in which rCFs can be introduced, which has a great impact for any commercial recycling operation (Line 2009). Processes, performance, commerciali- 


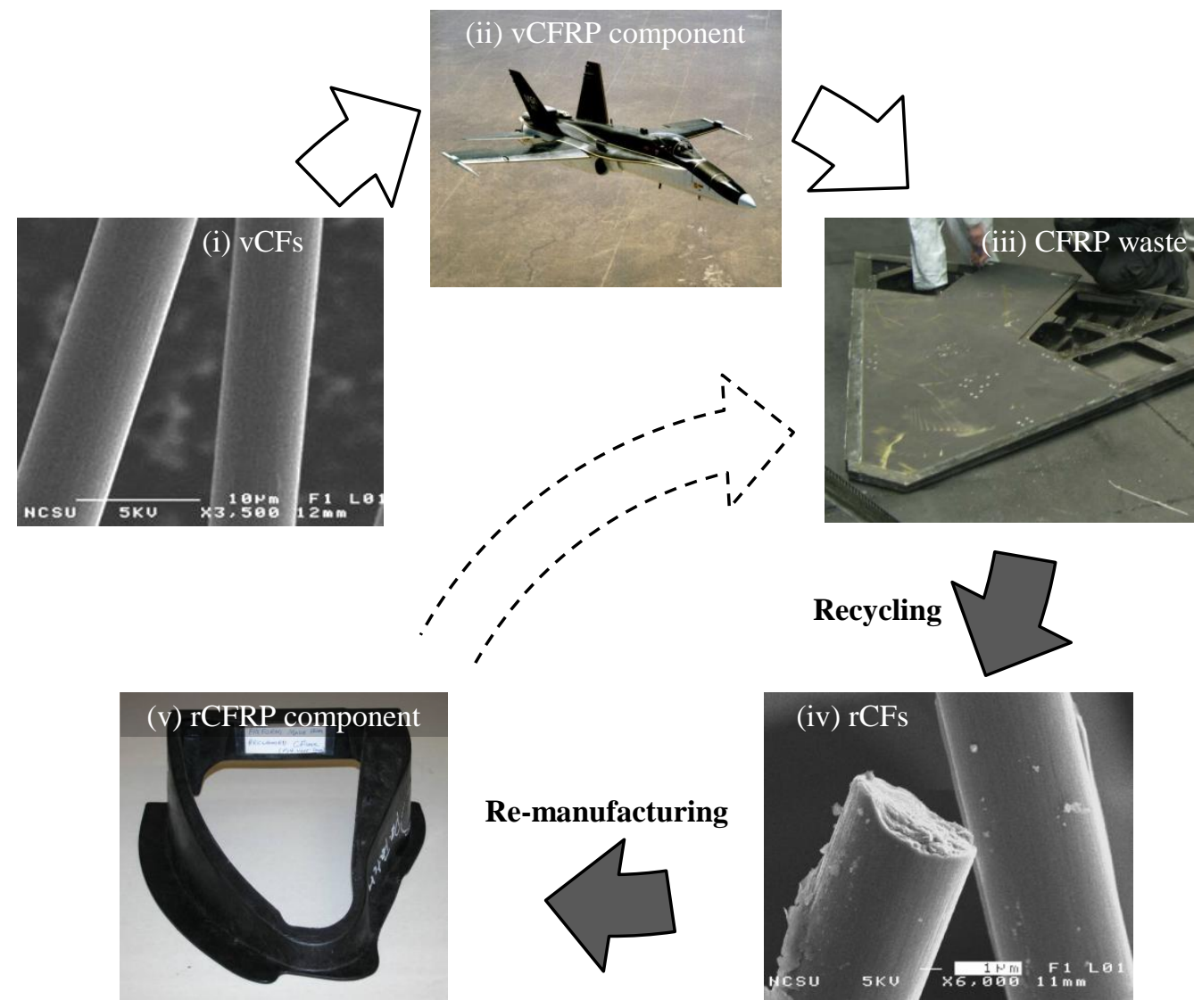

References:

(i) Connor 2008;

(ii) NASA 1991;

(iii) Marsh 2008;

(iv) Connor 2008;

(v) Janney et al. 2009.

Figure 2: Closed life-cycle for CFRPs.

sation and markets must therefore be considered altogether if a comprehensive analysis of CFRP recycling operations is envisaged.

This paper aims to fulfill this need: on the one hand, it encompasses the latest technical developments and the forthcoming commercialisation challenges; on the other hand, it relates the existing recycling and re-manufacturing processes to the final recyclates and their respective potential market applications.

The paper is organised as follows: Section 2 establishes the state of the art in carbon fibre recycling. Section 3 analyses re-manufacturing of recycled composites using rCFs. Section 4 discusses achievements and current issues with recycling operations, including technical, commercial and marketing considerations, all in the scope of structural applications. Finally, the main conclusions are summarised in Section 5. 


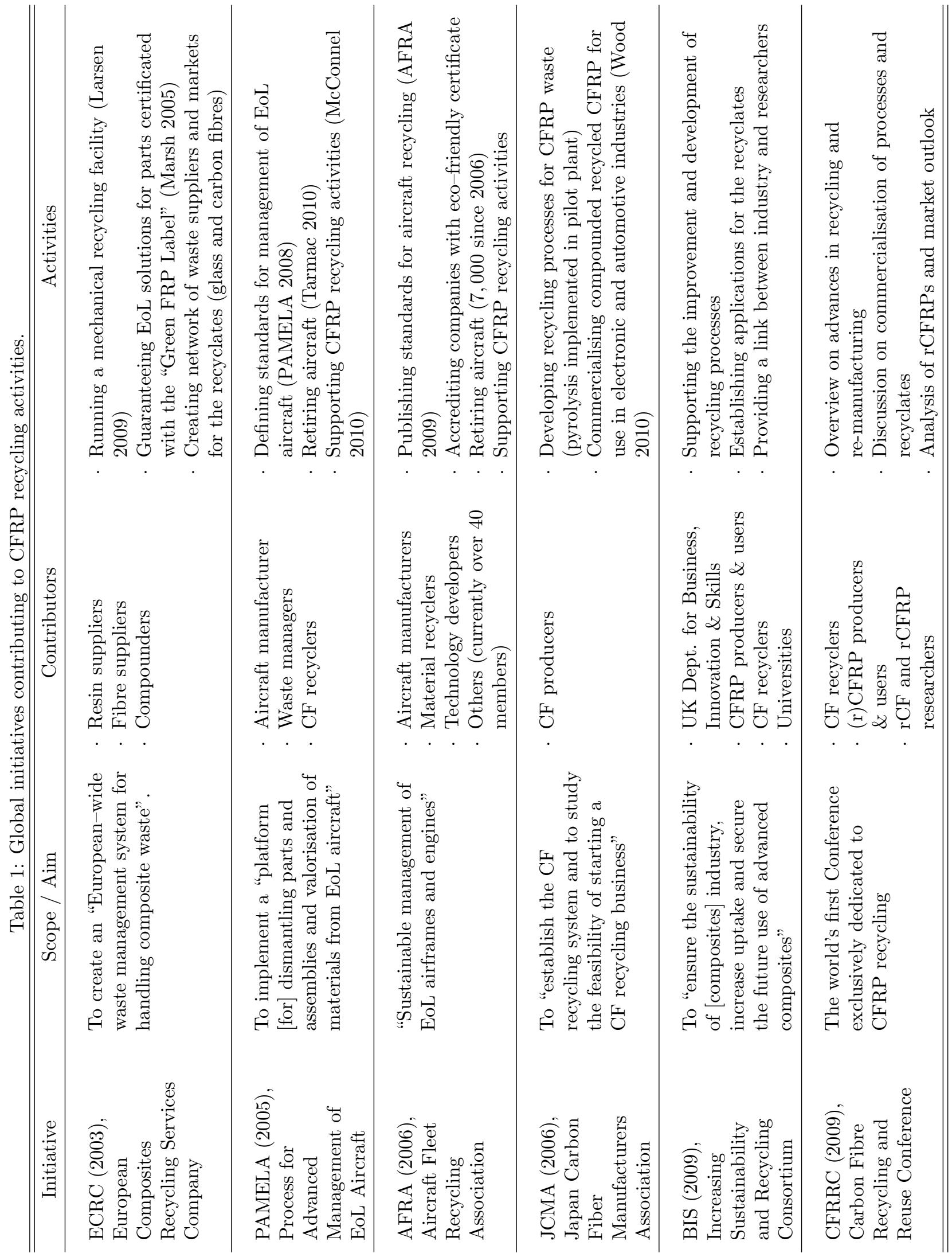




\section{Carbon fibre recycling processes}

\subsection{Technology families}

\subsubsection{Overview}

Two technology families have been proposed to recycle CFRPs (Figure 3): mechanical recycling and fibre reclamation. Both are addresses below, and a critical comparison is summarised in Table 2. Most efforts have been focusing on thermoset composites (e.g. carbon-epoxy systems), as their cross-linked matrix cannot be reprocessed simply by remelting (Pickering 2006).

\subsubsection{Mechanical recycling}

Mechanical recycling involves breaking-down the composite by shredding, crushing, milling, or other similar mechanical process; the resulting scrap pieces can then be segregated by sieving into powdered products (rich in resin) and fibrous products (rich in fibres) (Palmer et al. 2009, Pickering 2006).

Typical applications for mechanically-recycled composites include their re-incorporation in new composites (as filler or reinforcement, Pickering 2006) and use in construction industry (e.g. as fillers for artificial woods or asphalt, or as mineral-sources for cement, Conroy et al. 2006). However, these products represent low-value applications; mechanical recycling is therefore mostly used for glass fibre reinforced polymers (GFRPs), although applications to thermoplastic and thermoset CFRPs can be found as well (ECRC 2003, Kouparitsas et al. 2002, Ogi et al. 2007, Takahashi et al. 2007). Because mechanical recycling does not recover individual fibres, the mechanical performance of the recyclates is evaluated at the composite level (Table 5 in Section 3).

\subsubsection{Fibre reclamation}

Fibre reclamation consists on recovering the fibres from the CFRP, by employing an aggressive thermal or chemical process to break-down the matrix (typically a ther-

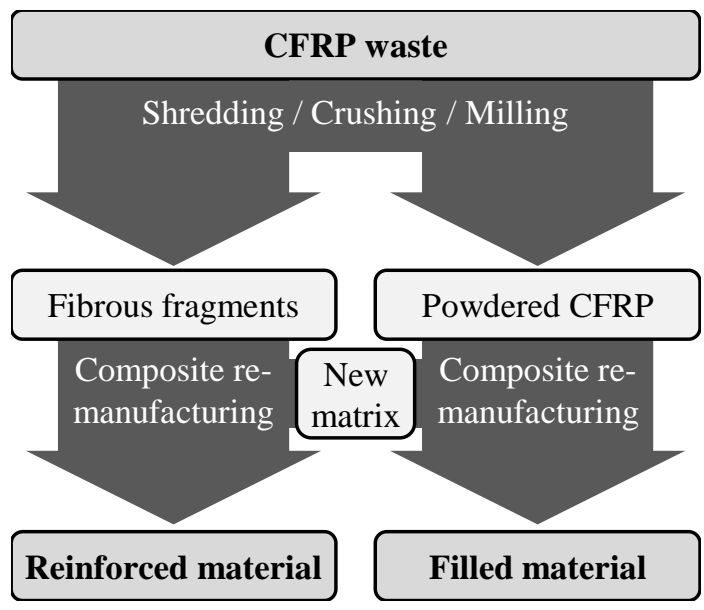

(a) Mechanical recycling.

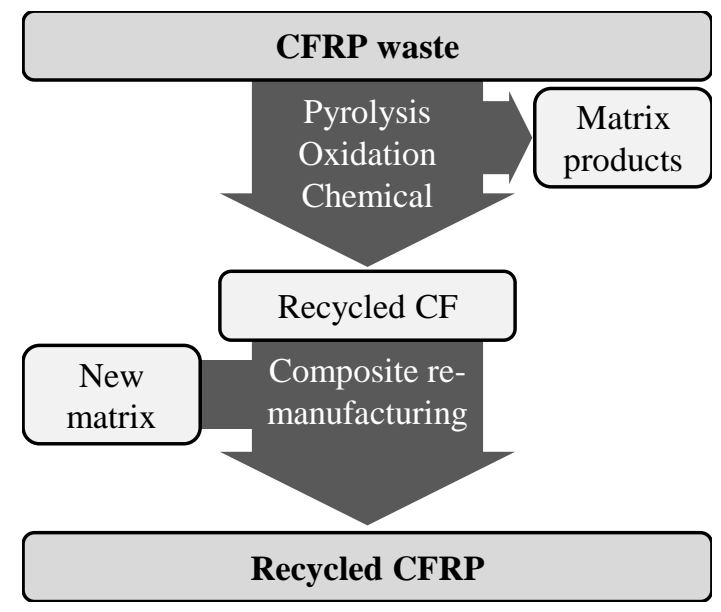

(b) Fibre reclamation.

Figure 3: Main technologies for CFRP recycling. 


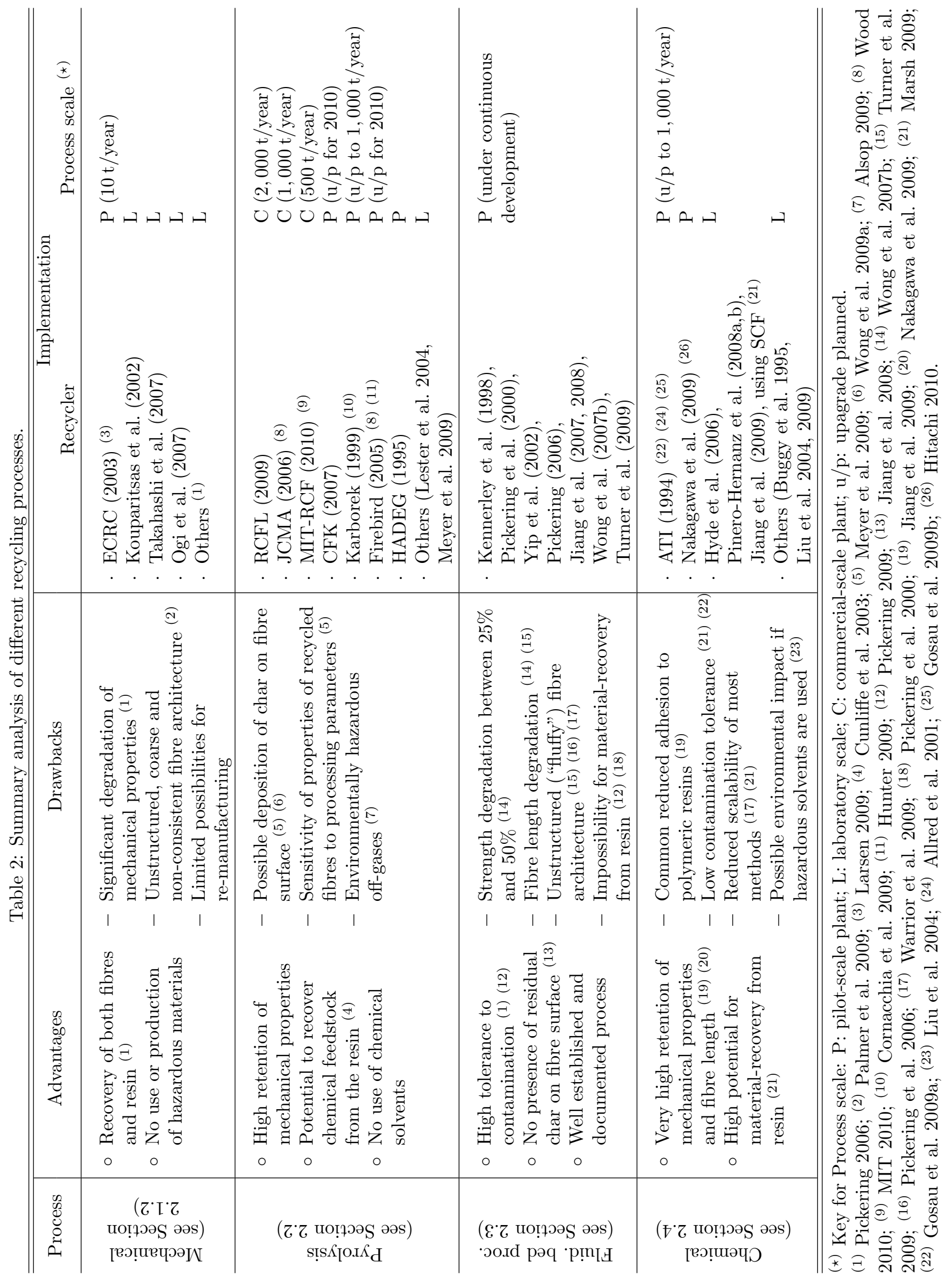


moset); the fibres are released and collected, and either energy or molecules can be recovered from the matrix. Fibre reclamation may be preceded by preliminary operations e.g. cleaning and mechanical size-reduction of the waste.

Fibre reclamation processes are particularly suitable to CFRPs: carbon fibres have high thermal and chemical stability (Pickering 2006), so usually their excellent mechanical properties are not significantly degraded (especially regarding stiffness). Generally, the rCFs have a clean surface (Figure 4a) and mechanical properties comparable to the virgin (v-) precursors (Figure 5); nevertheless, some surface defects (pitting, residual matrix and char, Figure 4b) and strength degradation (especially at longer gauge lengths, Heil et al. 2009) have also been reported.

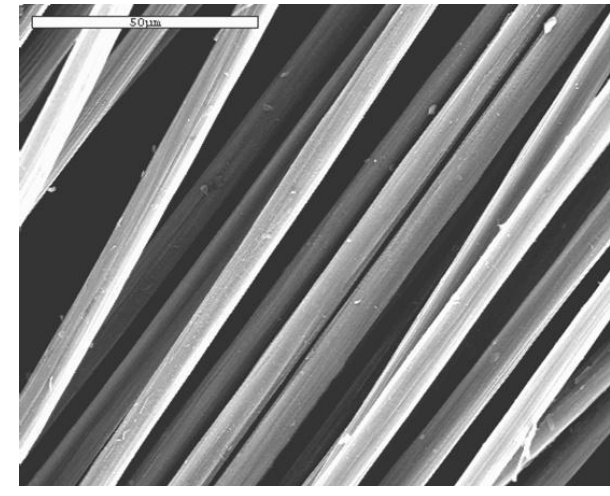

(a) Clean recycled fibres.

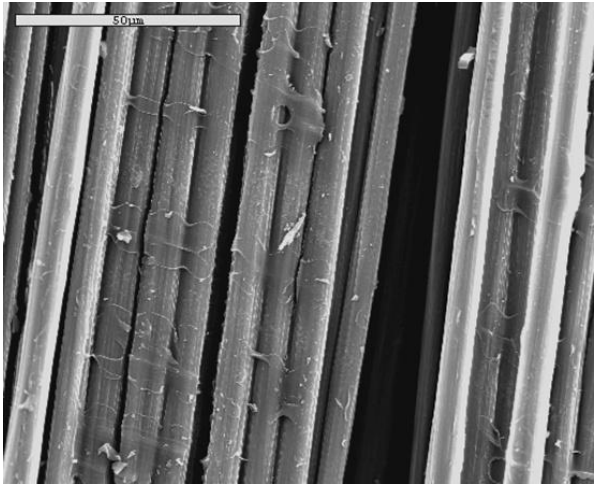

(b) Recycled fibres with char residue.

Figure 4: Scanning-electron microscopy of recycled (through pyrolysis) carbon fibres (Wong et al. 2009a).

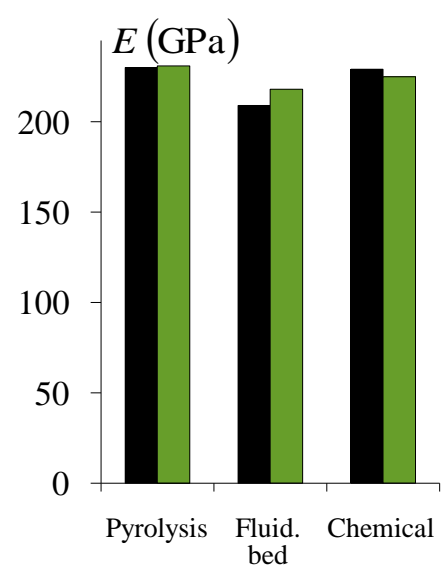

(a) Young's modulus.

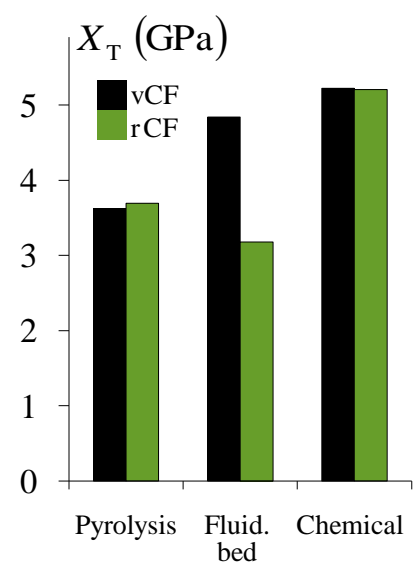

(b) Strength.

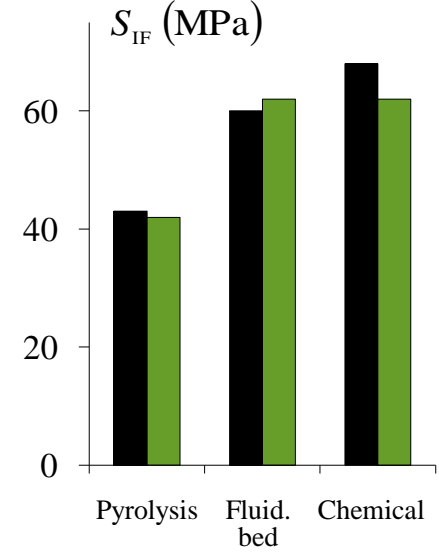

(c) Interfacial shear strength with epoxy resin.

Figure 5: Mechanical properties of recycled carbon-fibres and their virgin precursors (Jiang et al. 2009, 2008, Panesar 2009); see Sections 2.2 (pyrolysis), 2.3 (fluidised bed process), and 2.4 (chemical). 
Table 3: Mechanical properties of recycled CFs reclaimed through different processes.

\begin{tabular}{|c|c|c|c|c|c|}
\hline Process & $\operatorname{Recycler}^{(\star)}$ & Fibre type & $E^{\mathrm{f}}(\mathrm{GPa})^{(\dagger)}$ & $X_{\mathrm{T}}^{\mathrm{f}}(\mathrm{GPa})^{(\dagger)}$ & $S_{\text {IF }}(\mathrm{MPa})^{(\dagger)}$ \\
\hline \multirow{4}{*}{ 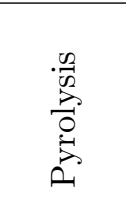 } & RCFL (2009) ${ }^{(1)}$ & Hexcel AS4 & $231(+0.4 \%)$ & $3.69(+2 \%)$ & $42(-2 \%)$ \\
\hline & Meyer et al. (2009) & Toho HTA & & $3.57(-4 \%)$ & \\
\hline & Karborek (1999) ${ }^{(2)}$ & Toray T800 & $222(-12 \%)$ & $4.62(-10 \%)$ & $99(+41 \%)$ \\
\hline & Lester et al. (2004) & Grafil 34-700 & $210(-13 \%)$ & $3.26(-20 \%)$ & \\
\hline $\begin{array}{c}\text { Fluid. } \\
\text { bed }\end{array}$ & $\begin{array}{l}\text { Jiang et al. (2008); } \\
\text { Wong et al. }(2007 b)\end{array}$ & Toray T600S & $218(+4 \%)$ & $3.18(-34 \%)$ & $62(+3 \%)$ \\
\hline \multirow{3}{*}{ 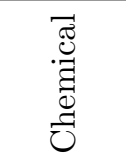 } & Allred et al. (2001) & Hexcel AS4 & & $3.37(-9 \%)$ & \\
\hline & Pinero-Hernanz et al. (2008a) & Toray T600S & $205(-15 \%)$ & $4.00(-2 \%)$ & \\
\hline & Jiang et al. (2009) & Toray T700S & $225(-2 \%)$ & $5.20(-0.3 \%)$ & $62(-9 \%)$ \\
\hline
\end{tabular}

(*) See Sections 2.2 (pyrolysis), 2.3 (fluidised bed process), and 2.4 (chemical recycling).

( $\dagger$ Values between brackets represent relative difference to virgin fibre.

(1) Mechanical properties measured by Connor (2008).

(2) Mechanical properties measured by Heil et al. (2009).

After reclamation, the recycled fibres are usually re-impregnated with new resin to manufacture recycled CFRPs (rCFRPs, Section 3). In addition, rCFs have also been used in non-structural applications (Section 4.3).

An overview on fibre reclamation processes is given in Sections 2.2 to 2.4. A critical comparison between them is established in Table 2, while Figure 5 and Table 3 present the mechanical properties of recovered fibres.

\subsection{Pyrolysis}

Pyrolysis, the thermal decomposition of organic molecules in an inert atmosphere (e.g. $\mathrm{N}_{2}$ ), is one of the most widespread recycling processes for CFRP. During pyrolysis, the CFRP is heated up to $450^{\circ} \mathrm{C}$ to $700^{\circ} \mathrm{C}$ in the (nearly) absence of oxygen; the polymeric matrix is volatilised into lower-weight molecules, while the CFs remain inert and are eventually recovered (Marsh 2008, Meyer et al. 2009). Advantages, drawbacks and current implementations of pyrolysis are summarised in Table 2; mechanical properties of reclaimed fibres are presented in Table 3.

In the UK, the Milled Carbon Group started developing a pyrolysis process for CFRP in a pilot-plant in 2003, and finally upgraded to "the world's first commercial scale continuous recycled carbon fibre operation" and formed Recycled Carbon Fibre Ltd. (RCFL 2009). Their process is implemented as a semi-open continuous-belt furnace with controlled atmosphere to avoid char formation; it complies with all legislation on the treatment (post-combustion) of off-gases, and the resin's calorific value is recovered and fed back in the process (material recovery from the polymer is not economically viable, Alsop 2009). The company has successfully reclaimed fibres from virtually all types of waste (Figure 1); the large dimensions and continuity of the furnace belt allow for entire out-of-date pre-preg rolls to be recycled while maintaining the architecture of 
the reinforcement. The group recently launched Green Carbon Fibre Ltd. (GCF 2010) for commercialisation of recycled products (e.g. milled and chopped fibres or pellets).

The Japan Carbon Fiber Manufacturers Association (JCMA 2006) started working on CFRP recycling in 2006. JCMA currently runs a pyrolysis plant, but details on the process itself and mechanical properties of fibres have not been disclosed (Wood 2010).

In the USA, Materials Innovation Technologies RCF (MIT-RCF) was created by the homonymous "advanced-materials solutions developer" company (MIT 2010), which had started recycling CFRP in 2008 using an undisclosed pyrolysis process (Janney et al. 2009). Their approach includes a preliminary step of chopping the feedstock to a consistent length; after pyrolysis, an in-house developed manufacturing process (three dimensional engineered preforming, 3-DEP) proved to be particularly suitable for re-manufacturing (Section 3).

In Germany, CFK Valley Stade Recycling GmbH \& Co. KG (CFK 2007) uses a continuous pyrolysis process (complemented with an oxidation step for char removal) developed together with the Technical University of Hamburg-Harburg and ReFiber ApS (Meyer et al. 2007). The process is suitable for several types of CFRP waste, and the main products comprise milled fibres, chopped fibres, and textile products (CFK 2007, McConnel 2010).

In Italy, Karborek S.p.a. (Karborek 1999) uses a combined pyrolysis and upgrading (in oxygen) patented process to recycle the fibres and avoid char formation (Cornacchia et al. 2009); although fibre-length is preserved during reclamation, Karborek's main products are milled and chopped rCFs, as well as blended non-woven veils with carbon and thermoplastic fibres (Section 3.3).

A variation of the pyrolysis process, using a continuous microwave approach (which avoids char formation, Lester et al. 2004) has been implemented by Firebird Advanced Materials, Inc., in the USA (Hunter 2009).

In Germany, HADEG Recycling Ltd. (HADEG 1995, working in collaboration with the Technical University of Hamburg-Harburg) reclaims CFs by pyrolysis, and also commercialises unprocessed manufacturing remainings (dry CF rovings or fabrics, and uncured pre-preg cut-offs).

\subsection{Oxidation in fluidised bed}

Oxidation is another thermal process for CFRP recycling; it consists in combusting the polymeric matrix in a hot and oxygen-rich flow (e.g. air at $450^{\circ} \mathrm{C}$ to $550{ }^{\circ} \mathrm{C}$ ). This method has been used by a few researchers (Jody et al. 2004), being the fluidised bed process (FBP) the most well-known implementation (Pickering 2006).

FBP has been developed and implemented by Pickering et al. (2000) at the University of Nottingham. Advantages and drawbacks of FBP are summarised in Table 2; mechanical properties of the reclaimed fibres are presented in Table 3.

During recycling, CFRP scrap (reduced to fragments approximately $25 \mathrm{~mm}$ large) is fed into a bed of silica on a metallic mesh. As the hot air stream passes through the bed and decomposes the resin, both the oxidised molecules and the fibre filaments are carried up within the air stream, while heavier metallic components sink in the 
bed; this natural segregation makes the FBP particularly suitable for contaminated EoL components. The fibres are separated from the air stream in a cyclone, and the resin is fully-oxidised in an afterburner; energy-recovery to feed the process is feasible (Pickering 2006, Pickering et al. 2000, Yip et al. 2002).

\subsection{Chemical recycling}

Chemical methods for CFRP recycling are based on a reactive medium - e.g. catalytic solutions (Allred et al. 2001), benzyl alcohol (Nakagawa et al. 2009), and supercritical fluids (Goto 2009, Jiang et al. 2009, Pinero-Hernanz et al. 2008a,b) — under low temperature (typically $<350{ }^{\circ} \mathrm{C}$ ). The polymeric resin is decomposed into relatively large (and therefore high value) oligomers, while the CFs remain inert and are subsequently collected (Marsh 2009).

Advantages, drawbacks and current applications of chemical recycling are summarised in Table 2; mechanical properties of reclaimed fibres are presented in Table 3.

In the USA, Allred et al. (2001) developed a "catalytic tertiary recycling process" for CFRP, in Adherent Technologies, Inc. (ATI 1994). The standard method consists on a proprietary low-temperature liquid catalysis (Allred et al. 2001), although contaminated waste may undergo a complementary dry pyrolysis step (Gosau et al. 2009a); with scrap preparation and post-treatment units, the whole process is automated and runs continuously (ATI 1994). The centre recycles both manufacturing waste (Allred et al. 2001, Gosau et al. 2009a) and EoL components (Connor 2008, Gosau et al. 2009b); the rCFs are marketed either milled or chopped, while resin products are recovered as fuels or chemical feedstock (ATI 1994).

In Japan, Nakagawa et al. (2009) developed a CF-epoxy recycling process using benzyl-alcohol and a catalyst in a $\mathrm{N}_{2}$ atmosphere. The plant (Hitachi 2010) includes a distillation system for cleaning the reaction fluid (which is then re-introduced in the system) and recovering resin-based products; it has reclaimed CFs from EoL components of sports and aeronautics industry.

Supercritical fluids (SCFs) are fluids at temperatures and pressures (typically just) above the critical point; at this stage, the fluid presents itself in one single supercritical phase, while having combined characteristics: liquid-like density and dissolving power, and gas-like viscosity and diffusivity (Eckert et al. 1996). SCFs can therefore penetrate porous solids and dissolve organic materials, while still being relatively innocuous under atmospheric conditions (Hyde et al. 2006). Several types of SCF (usually coupled with alkali catalysts) have been used for CF recycling, such as water (Pinero-Hernanz et al. 2008a), methanol (Pinero-Hernanz et al. 2008b), ethanol (Pinero-Hernanz et al. 2008b), acetone (Pinero-Hernanz et al. 2008b), and propanol (Hyde et al. 2006, Jiang et al. 2009, Pinero-Hernanz et al. 2008b). Chemical recycling with SCFs is a more recent approach; it is nevertheless already recognised for producing rCFs with virtually no mechanical degradation - especially when using propanol - and for allowing recovering useful chemicals from the matrix (Marsh 2009, Pickering 2009, Warrior et al. 2009). 


\section{Composites re-manufacturing}

\subsection{Introduction}

The second phase of $\mathrm{CF}$ reclamation processes (overview in Figure 3b) consists on re-impregnating the reclaimed fibres with a new matrix (Figure 6).

The rCFs are usually fragmented into short lengths, as a result of (i) size reduction of CFRP waste before reclamation, (ii) fibre breakage during reclamation, and (iii) chopping of the fibres after reclamation. In addition, all fibre reclamation processes remove the sizing from the fibres, so the recyclate is in a filamentised, random, low-density-packing (fluffy) form (Figure 7). Therefore, the existing manufacturing processes - developed for virgin materials, typically available as sized tows - must be adapted to the unique recycled-fibre form (Pickering 2009, Warrior et al. 2009).

An overview on re-manufacturing processes is given in Sections 3.2 to 3.5. A critical comparison between them is established in Table 4; Figure 8 and Table 5 present the mechanical properties of the different types of rCFRP.

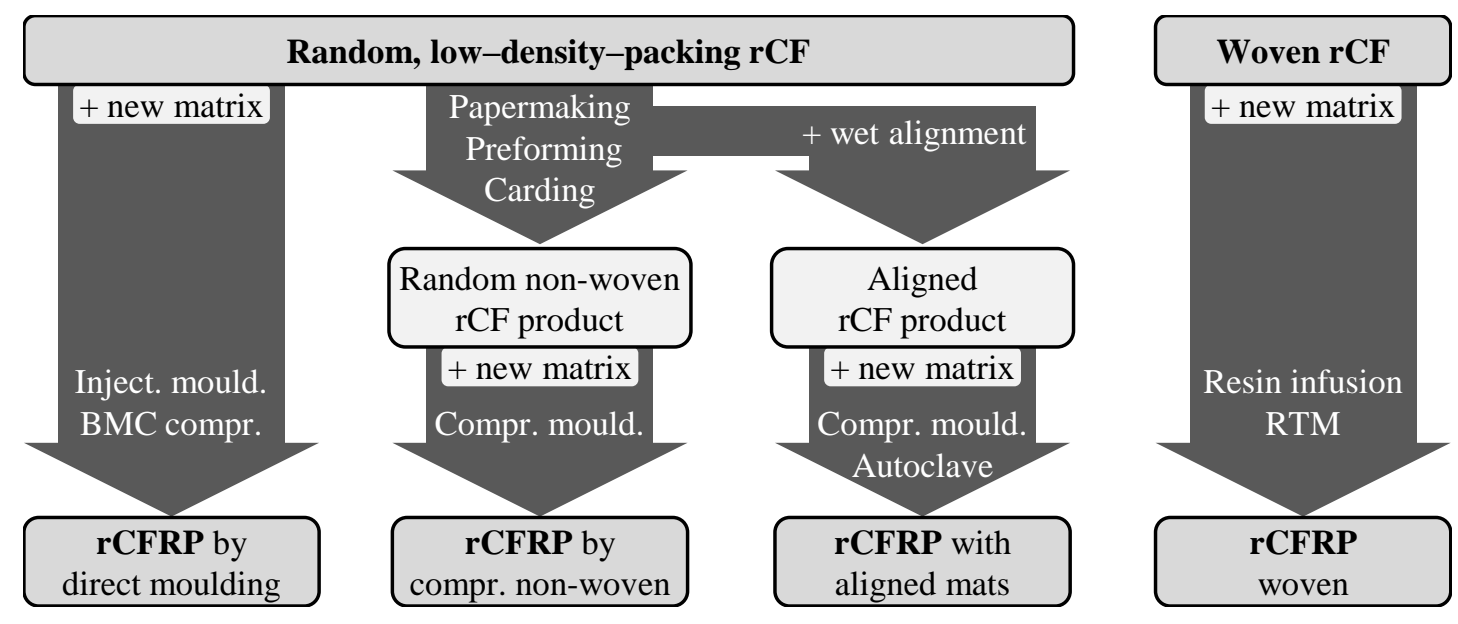

Figure 6: Re-manufacturing of rCFRPs.

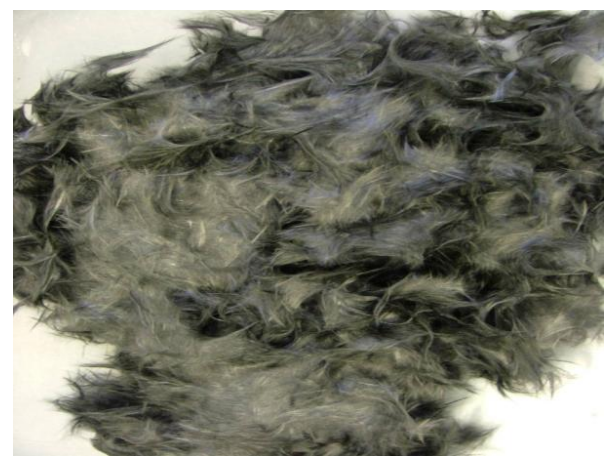

Figure 7: RCFs in a typical unsized, random, low-density-packing ("fluffy") form (Pickering 2009). 


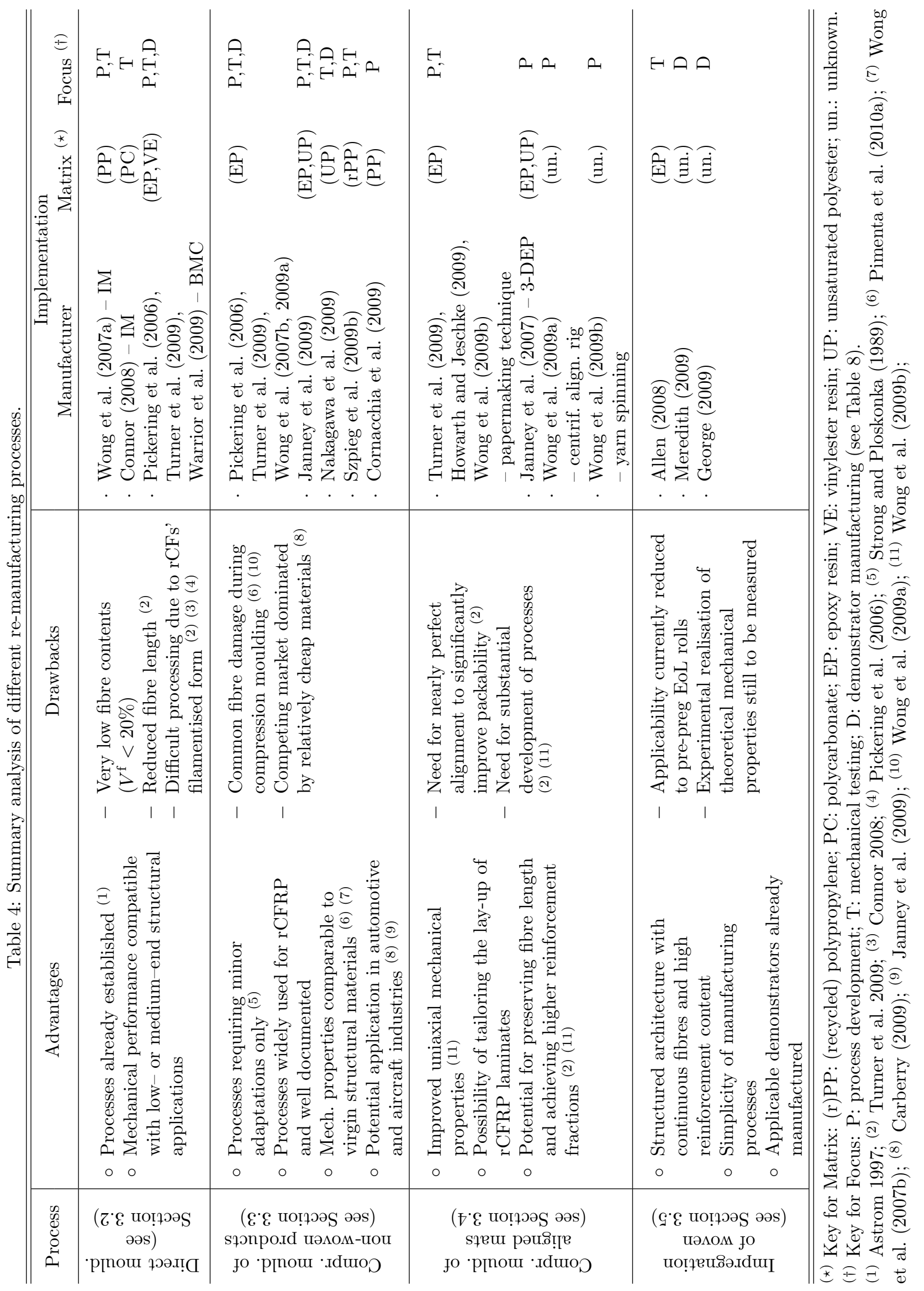




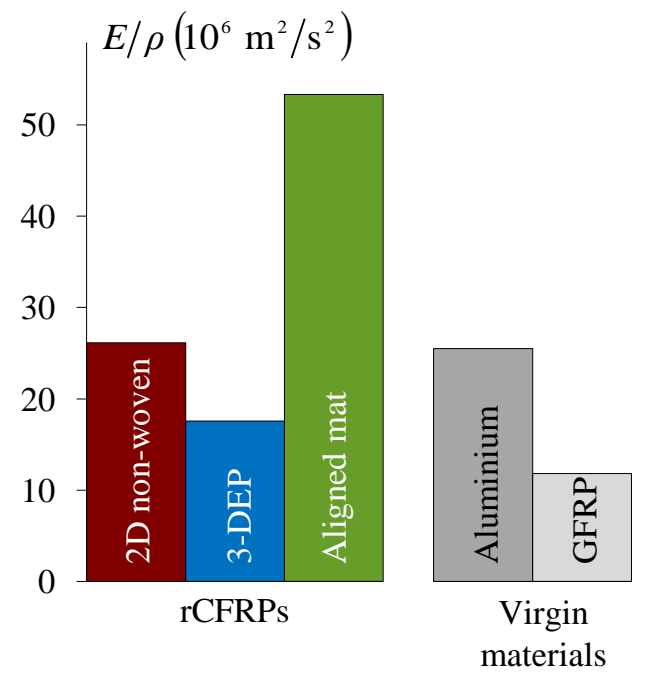

(a) Specific stiffness.

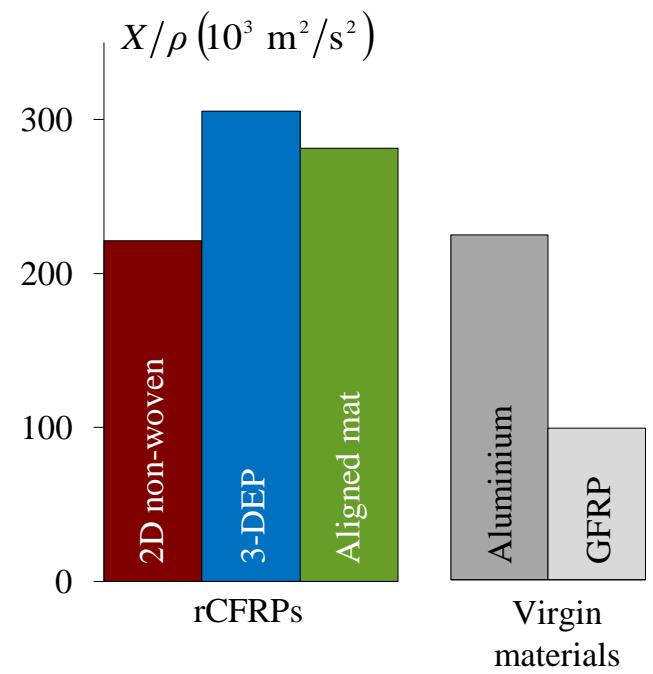

(b) Specific strength.

Figure 8: Mechanical properties of rCFRPs vs. conventional structural virgin materials. RCFRPs (see Sections 3.3 and 3.4) were produced from 2D non-woven mats (Wong et al. 2007b), 3-DEP process (Janney et al. 2009), and aligned mats (Turner et al. 2009); virgin materials (Wong et al. 2007b) are Aluminium 2024-T4 and GFRP for aircraft interiors (phenolic resin, $V^{\mathrm{f}}=31 \%$, short fibres).

Table 5: Mechanical properties of recycled CFRPs manufactured through different processes.

\begin{tabular}{lllllcc}
\hline \hline \multicolumn{1}{c}{ Process } & \multicolumn{1}{c}{ Manufacturer ${ }^{(\star)}$} & Matrix & $\begin{array}{c}V^{\mathrm{f}} \\
(\%)\end{array}$ & $\begin{array}{c}E_{\mathrm{T}} \\
(\mathrm{GPa})\end{array}$ & $\begin{array}{c}X_{\mathrm{T}} \\
(\mathrm{MPa})\end{array}$ & $\begin{array}{c}U_{\mathrm{imp}} \\
\left(\mathrm{kJ} / \mathrm{m}^{2}\right)\end{array}$ \\
\hline $\begin{array}{l}\text { Mechanical } \\
\text { recycling }\end{array}$ & Takahashi et al. (2007) & $\mathrm{PP}$ & 24 & $21^{(\mathrm{a})}$ & $101^{(\mathrm{a})}$ & \\
\hline $\begin{array}{l}\text { Injection } \\
\text { moulding }\end{array}$ & Ogi et al. (2007) & $\mathrm{ABS}$ & 24 & 12 & 102 & 19 \\
\hline BMC compr. & Connor (2008) & $\mathrm{PP}(\mathrm{b})$ & 19 & 16 & 126 & 27 \\
\hline $\begin{array}{l}\text { Compr. mould. } \\
\text { of non-woven } \\
\text { products }\end{array}$ & Wong et al. (2009a) & PC & 16 & 14 & 124 & \\
\hline $\begin{array}{l}\text { Compr. mould. } \\
\text { of alig. mats }\end{array}$ & Janney et al. (2009) & $\mathrm{EP}(\mathrm{c})$ & 10 & 20 & 71 & 8 \\
\hline \hline
\end{tabular}

(*) See Sections 2.1.2 (mechanical recycling), 3.2.2 (injection moulding), 3.2.3 (BMC compression), 3.3 (compr. mould. of non-woven products), and 3.4 (compr. mould. of aligned mats).

(a) Along preferential fibre direction.

(b) With 5\% (over fibre weight fraction) of G3003 MAPP coupling agent.

(c) Filled with calcium carbonate, moulded at $2 \mathrm{MPa}$.

(d) Recycled-CF feedstock with $l^{\mathrm{f}}=25 \mathrm{~mm}$.

(e) Flexural properties. 


\subsection{Direct moulding}

\subsubsection{Overview}

Injection moulding (IM) and bulk moulding compound (BMC) compression are two direct methods of remoulding rCFs into recycled composites. Advantages, drawbacks and applications of these processes are summarised in Table 4, and the mechanical properties of the composites are presented in Table 5.

\subsubsection{Injection moulding}

During IM, a mixture of resin (typically a thermoplastic), rCFs (short or milled) and fillers / additives is pre-compounded into pellets, which are subsequently injected into a mould (at $10 \mathrm{MPa}$ to $100 \mathrm{MPa}$ ) (Astrom 1997).

Wong et al. (2007a) injected rCFs (from FBP) with polypropylene (PP). The addition of coupling agents (maleic anhydride grafted polypropylene, MAPP) improved fibre-matrix adhesion and thus the overall mechanical properties (Table 5).

Connor (2008) manufactured and compared the performance of two injected CFRPs: one with virgin and another with recycled (from RCFL) carbon fibres. The recyclate (Table 5) was $25 \%$ less stiff than the virgin control; strength reduction was less pronounced (12\%), likely due to an improved fibre-matrix adhesion in the recyclate. The same process was not successful with fibres from ATI (1994), because of their more dispersed structure and poorer fibre-matrix adhesion.

\subsection{3. $B M C$ compression}

BMCs are intermediate products made by mixing resin (typically a thermoset), rCFs, fillers and curing agents into bulky charges; this premix is subsequently compression moulded (under 3.5 MPa to $35 \mathrm{MPa}$ ) into a component (Allen 2008, Astrom 1997).

Pickering et al. (2006) and Turner et al. (2009) moulded several BMCs with rCFs from the FBP and SCFs. The formulation of the BMC was tuned so as to overcome the poor flow properties of the resin and the filamentised and entangled form of the fibres. The main factors affecting the mechanical performance of the rCFRPs (especially the strength) were the fractions of fillers and of rCFs. The mechanical performance of the rCFRPs (optimised properties in Table 5) was superior to that of commercial glass BMCs (Warrior et al. 2009); however, it is not clear whether these rCFRPs can compete in price (Pickering et al. 2010).

\subsection{Compression moulding of intermediate non-woven products}

The production and subsequent re-impregnation of $2 \mathrm{D}$ or $3 \mathrm{D} \mathrm{rCF}$ non-woven dry products (with a short and random reinforcement architecture, Figure 9a) is one of the most widely used manufacturing processes for rCFRPs.

Several methods to produce the intermediate dry non-woven products are summarised in Table 6; the potential for fibre alignment (detailed in Section 3.4) is highlighted. Most techniques are similar to the production of Chopped Strand Mats (mostly applied to vGFRP, Strong and Ploskonka, 1989) or paper (TFP 2010). 


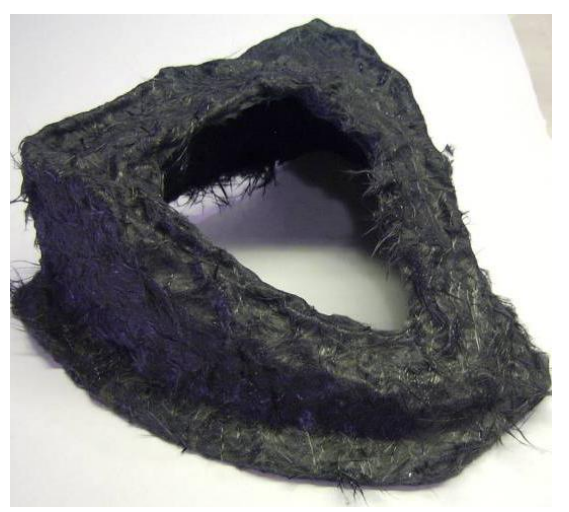

(a) 3D preform with random fibre orientation (Janney et al. 2009).

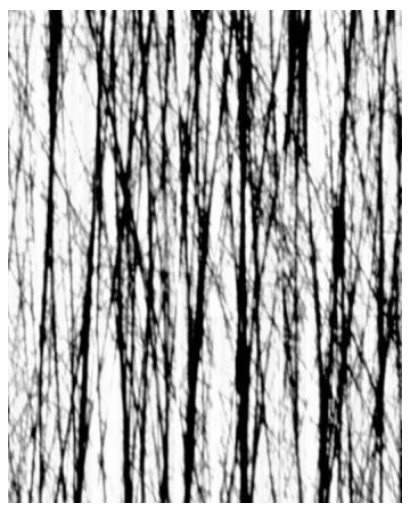

(b) Aligned 2D mat (Howarth and Jeschke 2009).

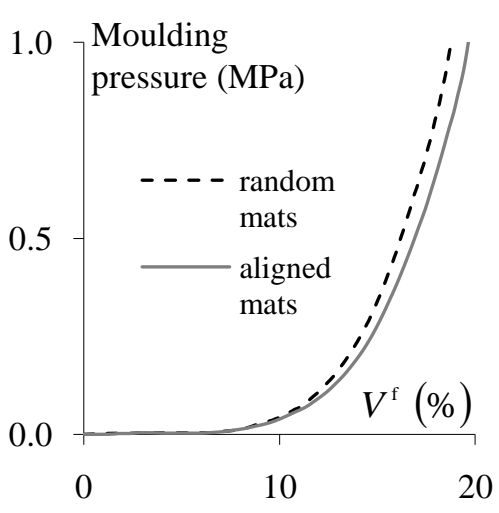

(c) Required moulding pressure for 2D mats (Turner et al. 2009).

Figure 9: Intermediate non-woven rCF products for compression moulding.

Table 6: Overview on manufacturing processes for non-woven intermediate products.

\begin{tabular}{clll}
\hline \hline Process & \multicolumn{1}{c}{ Manufacturer } & \multicolumn{1}{c}{$\begin{array}{c}\text { Overview } \\
\text { (see Section 3.3) }\end{array}$} & $\begin{array}{c}\text { Fibre alignment } \\
\text { (see Section 3.4) }\end{array}$ \\
\hline $\begin{array}{c}\text { Paper- } \\
\text { making } \\
\text { technique }\end{array}$ & $\begin{array}{l}\text { Turner et al. } \\
(2009), \text { Wong et al. } \\
(2007 \mathrm{~b}, 2009 \mathrm{a})\end{array}$ & $\begin{array}{l}\text { Industrial wet papermaking } \\
\text { (Howarth and Jeschke 2009, } \\
\text { TFP 2010, Wong et al. 2009b) }\end{array}$ & $\begin{array}{l}\text { Controllable preferential } \\
\text { alignment along moving belt }\end{array}$ \\
\hline $\begin{array}{c}\text { Wet } \\
\text { dispersion }\end{array}$ & $\begin{array}{l}\text { Szpieg et al. } \\
(2009 \mathrm{~b})\end{array}$ & In-house developed wet mixer & $\begin{array}{l}\text { Not possible in } \\
\text { current configuration }\end{array}$ \\
\hline $\begin{array}{c}\text { Carding } \\
\text { process }\end{array}$ & $\begin{array}{l}\text { Cornacchia et al. } \\
(2009)\end{array}$ & $\begin{array}{l}\text { Dry carding of rCF and } \\
\text { thermoplastic fibre hybrid mats }\end{array}$ & Unknown \\
\hline $\begin{array}{c}\text { Carding } \\
\text { process }\end{array}$ & Nakagawa et al. & Dry carding of rCF mats & Unknown \\
\hline $\begin{array}{l}\text { 3-DEP } \\
\text { process }\end{array}$ & Janney et al. & Deposition of chopped fibres on & $\begin{array}{l}\text { Controllable alignment using } \\
\text { multi-motions deposition tool }\end{array}$ \\
\hline \hline
\end{tabular}

The 2D or 3D non-woven dry products are then either compression moulded with resin layers (Pickering et al. 2006, Szpieg et al. 2009b), or re-impregnated through a liquid process (Janney et al. 2009). Advantages, drawbacks and applications of these processes are summarised in Table 4; mechanical properties of the rCFRPs are presented in Table 5.

Pickering et al. (2006), Turner et al. (2009) and Wong et al. (2007b, 2009a) produced 2D mats (in collaboration with Howarth and Jeschke, 2009, TFP 2010) with rCFs reclaimed through several processes (FBP, pyrolysis and SCF). Wong et al. (2009a) found that the random and filamentised form of the rCFs (enhanced by a filamentisation step) yielded mats with high loft and low permeability; this increased the moulding pressures (up to $14 \mathrm{MPa}$ for $V^{\mathrm{f}}=40 \%$ ), which consequently damaged the fibres during manufacture (down to only $10 \%$ of fibres longer than the critical length). Because of 
these issues, the rCFRP tensile strength saturated at $V^{\mathrm{f}}=30 \%$ (Wong et al. 2007b, 2009a); nevertheless, fibre-matrix adhesion was good, and the specific stiffness and strength of the optimised rCFRP compared favourably with virgin materials (Table 5 and Figure 8). Current work focuses on improving the mat-flow properties (e.g. by using thin mats down to 10 gsm, performing pre-compaction, reducing binder levels, filling the resin, Turner et al. 2009, Warrior et al. 2009), and studying alternatives to compression moulding (e.g. autoclave and out-of-autoclave curing, Turner et al. 2009, Warrior et al. 2009).

Janney et al. (2007, 2009) developed the three dimensional engineered (3-DEP) preforming process, initially for virgin fibres but also applicable to recyclates; the process consists on the deposition of chopped fibres (dispersed in water) on a porous forming screen mounted on a deposition tool, through application of vacuum (MIT 2010). The multiple-motions of the deposition tool enabled manufacturing of complex 3D parts (Figure 9a), with controlled fibre placement and orientation if required (detailed in Section 3.4). The researchers found that using constant fibre-lengths within each plate improved the permeability of the preforms during compression moulding (at $1.7 \mathrm{MPa}$ ) and, consequently, the mechanical performance of the rCFRP (Figure 8 and Table 5).

Nakagawa et al. (2009) manufactured sheet moulding compounds (SMCs) by carding the rCFs. The composite's tensile strength (Table 5) increased with the length of the rCFs fed to the carding machine up to a saturation point at $l^{\mathrm{f}} \approx 40 \mathrm{~mm}$.

Szpieg et al. (2009b) produced fully-recycled composites, with milled rCFs (supplied

by HADEG Recycling Ltd., $l_{\text {avg }}^{\mathrm{f}} \approx 200 \mu \mathrm{m}$ ) and reprocessed PP PURE manufacturing scrap (Szpieg et al. 2009a). Overall fibre content was $25 \%<V^{\mathrm{f}}<30 \%$, but resin rich regions were present; nevertheless, void content was only 1\%. Giannadakis et al. (2010) studied the material's mechanical response, including non-linear visco-elastic and plastic effects; current work focuses on improving performance.

Cornacchia et al. (2009) manufactured hybrid non-woven mats with their in-house recycled CFs and PP fibres, using a carding process and subsequent compression moulding (at $8 \mathrm{MPa}$ for $V^{\mathrm{f}}=30 \%$ ).

\subsection{Fibre alignment}

Fibre alignment (Figure 9b) is a key point to improve the mechanical performance of composites manufactured with discontinuous rCFs (Pickering 2009): not only the composite's mechanical properties improve along preferential fibre direction, as manufacturing requires lower moulding pressures (Figure 9c) and smoother fibre-to-fibre interactions (Turner et al. 2009, Wong et al. 2009b).

Advantages, drawbacks and applications of compression moulding of aligned mats are summarised in Table 4; mechanical properties of the rCFRPs are presented in Table 5.

The modified papermaking technique developed by Pickering (2009), Turner et al. (2009) and Warrior et al. (2009), in collaboration with Howarth and Jeschke (2009, TFP 2010), is a proprietary adaptation of the manufacturing process for random non-woven $2 \mathrm{D}$ mats. Currently, up to $80 \%$ of the theoretical UD alignment is reached (Figure $9 \mathrm{~b}$ ), 
using shorter rCFs and thin mats (down to $10 \mathrm{gsm}$ ). This method yielded rCFRPs with the highest mechanical properties ever reported (Figure 8 and Table 5); however, the filamentised $\mathrm{rCF}$ form reduced the impact energy to half of that typically measured for GFRP SMCs (Turner et al. 2009). Ongoing work focuses on improving packability of mats and through-the-thickness uniformity of alignment (Turner et al. 2009, Wong et al. 2009b).

The 3-DEP process (Section 3.2) developed by Janney et al. (2007) was used to produce a vCFRP cone with fibres preferentially aligned circunferentially; this was achieved by adjusting the position and motion of the deposition tool.

A centrifugal alignment rig was presented by Wong et al. (2009b); it uses a rotating drum equipped with a convergent nozzle, which aligns a highly-dispersed suspension of rCFs. The use of shorter fibres (down to $l^{\mathrm{f}} \approx 5 \mathrm{~mm}$ ) improved the rCFRP alignment obtained (up to $90 \%$ ).

A yarn spinning technique is under development by Wong et al. (2009b), within the FibreCycle project (Marsh 2009). Wet dispersions of rCFs are transported through a pipe with an induced vortex; under optimised conditions, spun yarns with 50 filaments and $60 \mathrm{~mm}$ long are produced.

\subsection{Woven rCFRP}

As some recycling processes can preserve the reinforcement architecture of the waste (Section 2), it is possible to recover the structured weave from large woven items, e.g. out-of-date pre-preg rolls, EoL aircraft fuselage, or pre-preg trimmings from large components; re-impregnating (through e.g. resin transfer moulding (RTM) or resin infusion) the recycled weave fabrics then produces woven rCFRPs. With currently available recycling processes, stiffness and strength could theoretically reach more than $70 \mathrm{GPa}$ and $700 \mathrm{MPa}$ respectively; moreover, fabrics reclaimed from pre-preg rolls would be fully traceable. Advantages, drawbacks and applications of this process are summarised in Table 4.

Allen (2008) used woven fabrics from undisclosed recyclers; the mechanical prop-

erties of the rCFRPs were poor when compared to similar vCFRPs (especially tensile strength), due to fibre degradation during recycling.

Meredith (2009) applied woven rCFRP to non-critical parts of an environmentally sustainable Formula-3 car (Figure 10c); the car also uses other recycled and natural materials (e.g. potato starch) and bio-fuels (e.g. derivatives from chocolate oil).

George (2009) produced a rCFRP tool (Janicki 2010) for composite lay-up in aircraft manufacturing.

\section{Discussion}

\subsection{State of the art and outlook in recycling and re-manufacturing technologies}

Three methods for recovering clean fibres from CFRP waste were identified: pyrolysis, oxidation in fluidised bed, and chemical recycling (Table 2). Pyrolysis is currently the only process with commercial-scale implementations (JCMA 2006, MIT 2010, 


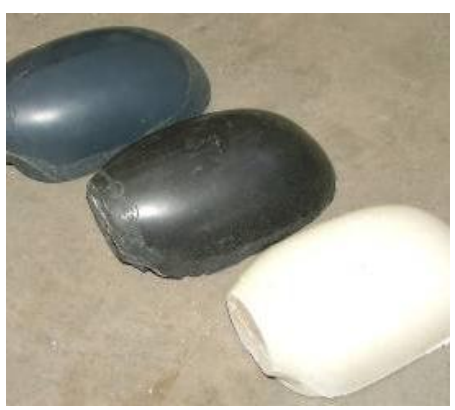

(a) Wing mirror covers (BMC compression, Warrior et al. 2009).

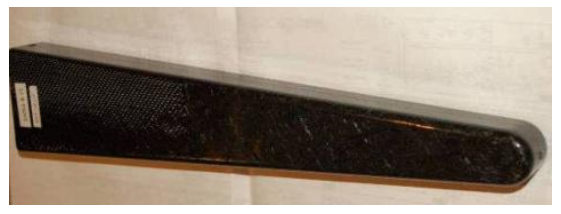

(b) Aircraft seat arm-rest (3-DEP process, George 2009).

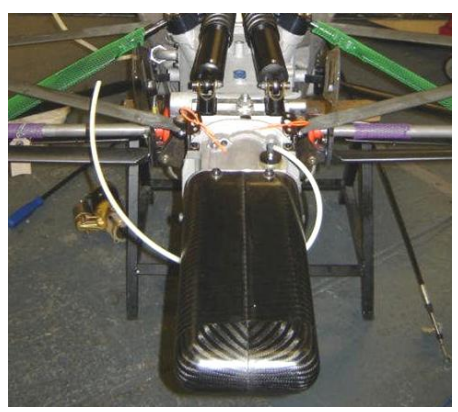

(c) Rear or WorldFirst F3 car (woven re-impregnation, Meredith 2009).

Figure 10: Examples of demonstrators manufactured with recycled CFs.

RCFL 2009); some chemical methods are advantageous regarding the mechanical performance of the rCFs (Jiang et al. 2009, Warrior et al. 2009), while the fluidised bed process is particularly interesting for EoL components and contaminated waste (Pickering 2006).

Mechanical degradation is usually minor in all optimised processes apart from the fluidised bed (Figure 5 and Table 3), although it depends on fibre type and length (Heil et al. 2009). Current estimatives suggest that reclaiming rCFs requires only a small fraction of the resources for producing vCFs (Table 7), so recycling CFRP appears to be economically and environmentally viable. The main technical challenges relate now to waste preparation, recycling of EoL parts, and quality control of rCFs (Hunter 2009, Line 2009, Pickering 2009).

Research on rCFRP manufacturing is still on-going, as the entangled and unsized rCF form requires existing methods to be adapted. Re-impregnating non-woven mats is one of the most effective methods in terms of the mechanical performance of the composites (Janney et al. 2009, Warrior et al. 2009, Wong et al. 2009a); properties are at the level of structural virgin materials e.g. GFRPs, short-fibre CFRPs and aluminium (Figure 8 and Table 5).

Further technical developments in re-manufacturing technologies are still needed, especially regarding inducing fibre alignment, increasing fibre content, and decreasing fibre damage during processing (Pickering 2009, Pimenta et al. 2010a). The performance of most rCFs is similar to that of virgin fibres, so recycled composites could in principle reach the properties of ${ }_{\mathrm{vCFRPs}}$ with comparable architectures if suitable re-manufacturing processes were developed.

Table 7: Estimated values for the cost of carbon fibres (Carberry 2008).

\begin{tabular}{ccc}
\hline \hline Fibre type & Manufacturing energy $(\mathrm{kWh} / \mathrm{kg})$ & Price $(£ / \mathrm{kg})$ \\
\hline $\mathrm{vCF}$ & $55-165$ & $20-40$ \\
$\mathrm{rCF}$ & $3-10$ & $11-16$ \\
\hline \hline
\end{tabular}


Table 8: Demonstrators manufactured with recycled CFs.

\begin{tabular}{|c|c|c|c|c|}
\hline $\begin{array}{c}\text { rCFRP } \\
\text { demonstrator }^{(\star)}\end{array}$ & $\begin{array}{c}\text { Virgin } \\
\text { component }\end{array}$ & $\begin{array}{c}\mathrm{CF} \\
\text { recycler } \\
\text { (see Section 2) }\end{array}$ & $\begin{array}{c}\text { rCFRP } \\
\text { manufacturer } \\
\text { (see Section 3) }\end{array}$ & $\begin{array}{l}\operatorname{rCFRP}_{\operatorname{matrix}^{(\dagger)}}\end{array}$ \\
\hline $\begin{array}{l}\text { Wing mirror } \\
\text { cover }\end{array}$ & Unknown & Unknown & $\begin{array}{l}\text { Warrior et al. } \\
\qquad(2009)\end{array}$ & $\mathrm{UP}$ \\
\hline $\begin{array}{l}\text { Car door } \\
\text { panel }\end{array}$ & Unknown & Unknown & $\begin{array}{c}\text { Warrior et al. } \\
(2009)\end{array}$ & $\mathrm{EP}$ \\
\hline Corvette wheelhouse & $\begin{array}{c}\text { EoL F-18 aircraft } \\
\text { stabiliser }\end{array}$ & RCFL (2009) & $\begin{array}{c}\text { Janney et al. } \\
(2009)\end{array}$ & $\mathrm{UP}$ \\
\hline $\begin{array}{l}\text { Aircraft seat arm rest } \\
\text { (George 2009) }\end{array}$ & $\begin{array}{l}\text { Aircraft testing \& } \\
\text { manufact. waste }\end{array}$ & $\begin{array}{l}\text { Janney et al. } \\
(2009)\end{array}$ & $\begin{array}{c}\text { Janney et al. } \\
(2009)\end{array}$ & $\mathrm{EP}$ \\
\hline $\begin{array}{l}\text { Driver's seat of a Student } \\
\text { Formula SAE car }\end{array}$ & Tennis rackets & $\begin{array}{c}\text { Nakagawa et al. } \\
(2009)\end{array}$ & $\begin{array}{c}\text { Nakagawa et al. } \\
(2009)\end{array}$ & UP \\
\hline $\begin{array}{l}\text { Rear structure of } \\
\text { WorldFirst F3 green car }\end{array}$ & $\begin{array}{l}\text { Outdated woven } \\
\text { pre-preg }\end{array}$ & RCFL (2009) & Meredith (2009) & $\mathrm{EP}$ \\
\hline $\begin{array}{l}\text { Tool for composite } \\
\text { lay-up }\end{array}$ & $\begin{array}{l}\text { Outdated woven } \\
\text { pre-preg }\end{array}$ & RCFL (2009) & George (2009) & un. \\
\hline
\end{tabular}

${ }^{\star} \star$ Additional information can be found in the reference associated with the rCFRP manufacturer, unless otherwise here specified.

(†) Key for rCFRP matrix: EP: epoxy resin; UP: unsaturated polyester; un.: unknown.

A few structural components have been manufactured with rCFRPs as technology demonstrators: crashworthy and secondary components for the automotive industry, components for aircraft interiors, and tooling (Figure 10 and Table 8).

\subsection{Forthcoming challenges to the commercialisation of $r C F s$}

In addition to the technical challenges identified in the previous section, the major current challenge to CFRP recycling operations is the establishment of a sound CFRP recycling chain supporting the effective commercialisation of recycling processes and products. The main issues to overcome, as identified by academics, recyclers, end-users and governments, are:

- Global strategy: organised networks for CFRP recycling (Table 1) - bringing together suppliers / users (composite-related industries), recyclers and researchers - must be created, so as to understand the current state of the art and plan for future developments on the topic according to industrial needs (BIS 2009).

- Incentives for recycling: governments should support the option of recycling; this could involve not only penalties for non-recyclers (e.g. landfilling taxes) but also direct privileges (e.g. carbon credits) for companies recycling their CFRP waste (Line 2009).

- Implementing suitable legislation: there is currently a void in specific legislation covering the CFRP recycling operations. For instance, the classification of 
pyrolysis processes for CFRP recycling should be distinguished from that of traditional pyrolysis processes (Alsop 2009); a suitable classification of CFRP waste for international transport to recycling units needs to be approved.

- Logistics and cooperation in the supplying chain: waste suppliers must cooperate with recyclers, which includes supplying the waste in a continued and suitable form (Hunter 2009, Marsh 2008) and providing the recyclers with material certificates whenever possible (e.g. for out-dated prepreg rolls) (Line 2009). Conversely, recyclers must ensure that materials and components supplied will not undergo reverse engineering.

- Market identification and product pricing: this requires that (i) characteristics and properties of different rCFRPs are known, (ii) their processing times and costs are assessed, and (iii) the value for the recycled label is established (Line 2009).

- Life-cycle analysis: the environmental, economic and technical advantages of rCFRPs over other materials and disposal methods can be estimated only through cradle-to-grave analyses of the whole CFRP life-cycle.

- Market establishment: ultimately, the major current challenge for the success of CFRP recycling is the establishment of a market for the recyclates; this is recognised by leading researchers (Pickering 2006, 2009), CF recyclers (Line 2009), CF users (George 2009), and analysts (McConnel 2010, Wood 2010). Creating a market requires all the previous issues to be overcome, so rCFs are accepted as an environment-friendly and cost-effective material.

\subsection{Development of structural applications for rCFRPs}

One of the most promising applications for rCFRPs consists of non-critical structural components (George 2009, Pickering 2006, 2009). Although there are currently non-structural applications for rCFs - e.g. industrial paints, construction materials, electromagnetic shielding, high performance ceramic brake discs, fuel cells (Curry 2010, Howarth and Jeschke 2009, Panesar 2009, Pickering 2006) — structural applications would fully exploit the mechanical performance of the fibres, thus increasing the final value of recycled products.

The aeronautics industry is particularly interested in incorporating rCFRPs in the interiors of aircraft (Carberry 2009, George 2009), as long as the materials are traceable and their properties consistent (which may easily achieved when the feedstock is manufacturing waste). Certification of recycled materials might not be viable in the short term, and it is recognised that rCFRPs should be allowed to mature in non-aeronautical applications first (George 2009); nevertheless, the involvement of aircraft manufacturers in CFRP recycling (e.g. in AFRA (2006) and PAMELA (2008) projects) and their effort in identifying suitable applications for the recyclates (specifically in aircraft interiors) suggests that rCFRPs might be incorporated back into non-critical aeronautical applications in a foreseeable future. 
There is also scope to manufacture automotive components with rCFRPs, not only for technical or economic reasons, but also to boost green credentials. As legislation tightened regarding recyclability and sustainability (EU 2000/53/EC 2000), the automotive industry grew interest for natural composites (Ellison and McNaught 2000), which are nowadays widely used in mass production despite some associated problems (e.g. consistency of feedstock); rCFRPs could follow as an environmental-friendly material with improved mechanical performance.

Currently, structural demonstrators manufactured with rCFRPs are aimed at aircraft or automotive industries (Figure 10, Table 8); other markets have also been identified, such as construction industry, sports and household goods, and wind turbines (Pickering 2006, Pickering et al. 2010). Table 9 provides a comprehensive overview of potential applications for several types of rCFRPs; this is complemented by specific applications currently manufactured with virgin materials, to allow for a direct comparison regarding manufacturing methods and mechanical properties.

\subsection{Multiscale analysis of the mechanical response of rCFRPs}

General studies on the mechanical behaviour of rCFRPs (Connor 2008, Giannadakis et al. 2010, Janney et al. 2009, Nakagawa et al. 2009, Turner et al. 2009, Wong et al. 2009a) are valuable to validate the recycling processes and to identify major weaknesses in the recyclates. They also reveal how complex and unique the architecture of rCFRPs can be, and how essential it is to investigate their mechanical response in-depth (Gibson 2010, Pickering 2009).

Understanding the relations between microstructure, mechanical properties and damage mechanisms of rCFRPs provides informed guidance for reclaimers and manufacturers towards recyclates with optimal structural performance. Moreover, this understanding supports design methods for rCFRPs, which are essential for the establishment of a structural applications market. Given the urgency in closing the loop on the CFRP life-cycle, analysing the mechanical response of rCFRPs at the micro and macromechanical levels has become critical for the continued use of composites.

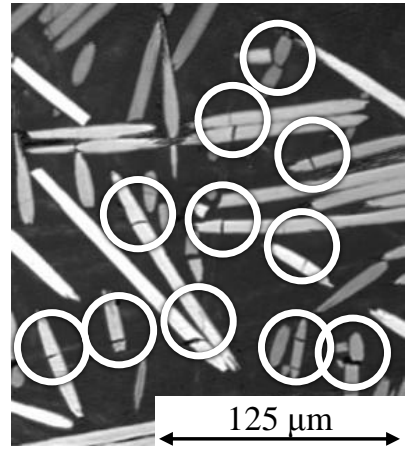

(a) Fibres fractured during manufacture.

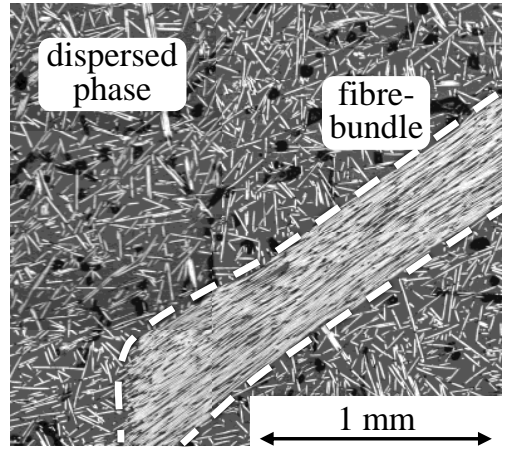

(b) RCFRP architecture: dispersed fibres and bundles.

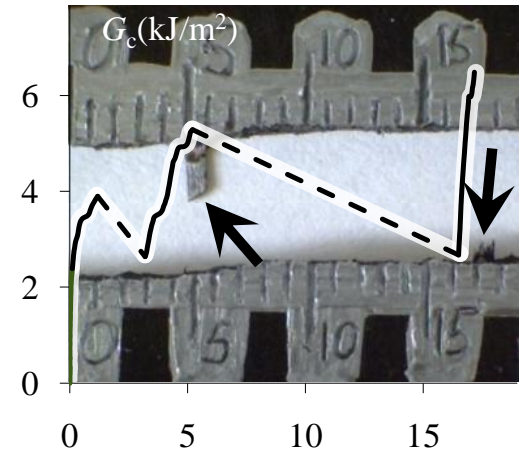

(c) Increase of fracture toughness near fibre bundles.

Figure 11: Aspects of the mechanical response of a non-woven random rCFRP (Pimenta et al. 2010a). 


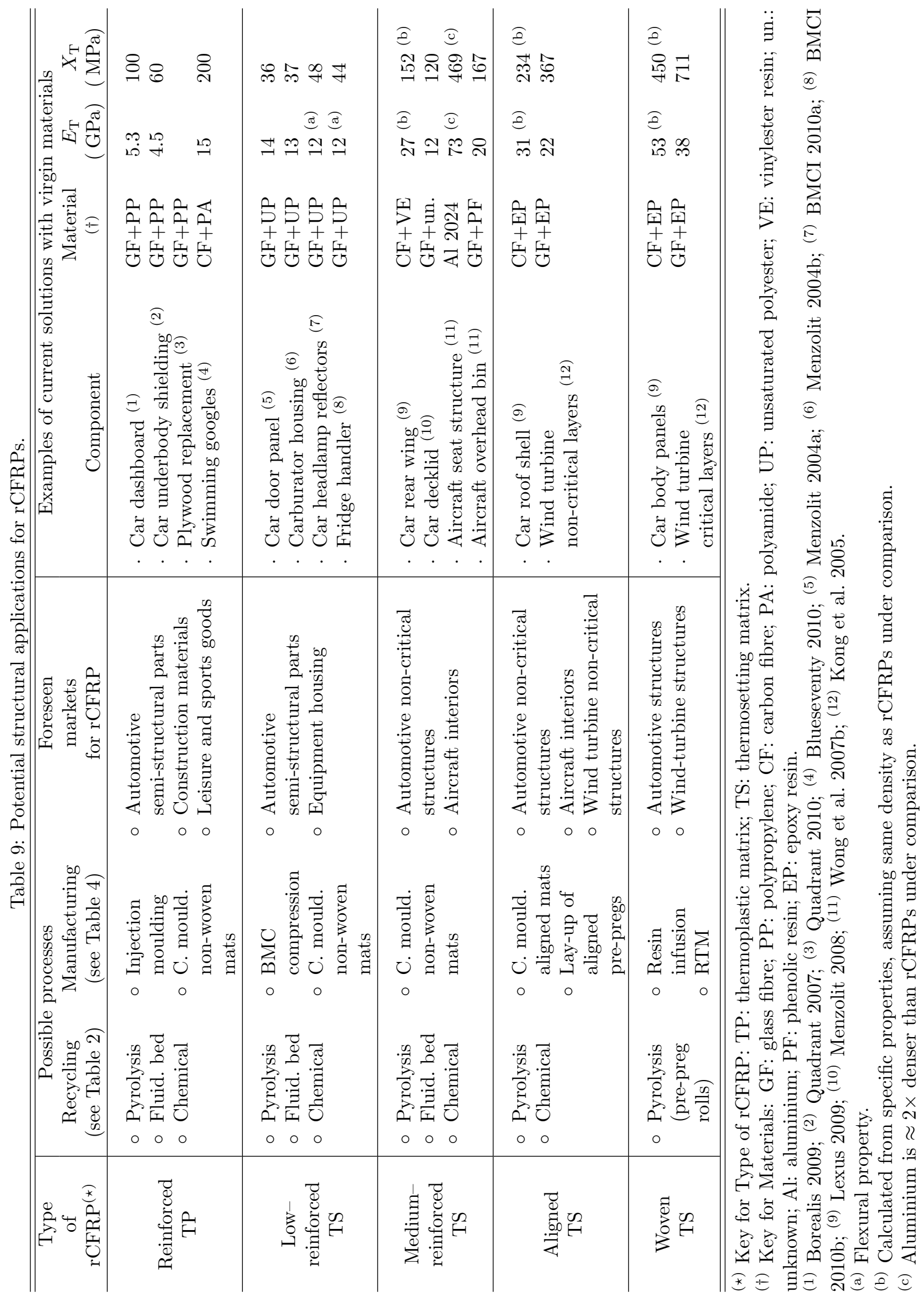


A detailed multiscale mechanical study of a state-of-the-art rCFRP (manufactured at the University of Nottingham with fibres reclaimed at RCFL) was performed at Imperial College London (Pimenta et al. 2010a); microstructure, mechanical properties, and failure and toughening mechanisms were investigated, and the influence of recycling and re-manufacturing processes analysed. The study showed that the extensive breakage of fibres during re-manufacturing lead to a considerable degradation of tensile strength at the composite level (Figure 11a); in addition, it was found that fibre bundles - held together by minimal amounts of residual matrix not completely pyrolysed increase the in-plane fracture toughness of the material (Figures 11b and 11c).

The work by Pimenta et al. (2010a) proved that a feature usually seen as a recycling defect - incomplete removal of matrix — can actually enhance the mechanical response of the recyclates, which illustrates the need for a comprehensive approach towards the optimisation of processes. In addition, the experimental observations were used to develop multiscale analytical models to predict the properties of recycled composites (Pimenta et al. 2010b), which can be used in the design of rCFRP structural components. As recycling and re-manufacturing processes evolve, other types of rCFRPs can be analysed in a similar framework.

\section{Conclusions}

A comprehensive overview on the state of the art and market outlook for CFRP recycling operations was presented; recycling and re-manufacturing processes were reviewed, and the commercialisation challenges and potential markets for the recyclates were identified.

A critical comparison between recycling processes proved each of them to have specific advantages and drawbacks, suggesting complementarity rather than competition. Most of recycling processes yield rCFs with high retention of mechanical properties, and a few commercial-scale plants already exist (Tables 2 and 3 ).

Re-manufacturing composites with rCFs was found to be challenging, especially regarding achieving high mechanical properties; research is therefore still on-going. Nevertheless, the mechanical performance of some rCFRPs overcomes that of some conventional structural materials, and a few structural demonstrators for the automotive and aircraft industries have been manufactured (Tables 4 to 6 and 8).

It has been shown that establishing applications for the recyclates is the key to finally close the loop in the CFRP life-cycle. The technical feasibility of re-introducing the recyclates in the non-critical structural market has been demonstrated, and specific potential applications have been suggested (Table 9). Nevertheless, there are still several non-technical issues which need to be overcome; in that sense, collaborative organisations focusing on the whole chain of CFRP recycling are essential (BIS 2009).

Researchwise, more detailed, multiscale and systematic studies on the mechanical performance of rCFs and rCFRPs are needed, so as to increase the acceptance of recyclates as structural materials by engineers and designers. It is also essential to perform 
life-cycle analyses of the several recycling and re-manufacturing methods, to assess cost effectiveness and environmental impact of using rCFs.

\section{Acknowledgments}

The funding from the Portuguese Foundation for Science and Technology (project nr. SFRH/BD/44051/2008) is gratefully acknowledged.

The authors gratefully acknowledge Prof. S. J. Pickering (from the University of Nottingham), Mr. S. Line, Mr. S. Alsop and Mr. S. Johnson (from Recycled Carbon Fibre Ltd., UK), and Mr. P. George and Mr. W.Carberry (from The Boeing Company) for many helpful discussions.

\section{References}

AFRA, 2006. Aircraft Fleet Recycling Association. Official website at www . afraassociation.org (last accessed July 2010) .

AFRA, 2009. Best Management Practice for Management of Used Aircraft Parts and Assemblies. AFRA Board, available online at www.afraassociation.org/ AFRAPartsBMPv2_2.pdf.

Allen, B.E., 2008. Characterization of Reclaimed Carbon Fibers and their Integration into New Thermoset Polymer Matrices via Existing Composite Fabrication Techniques. Master Thesis. North Carolina State University, Raleigh, NC, USA.

Allred, R.E., Gosau, J.M., Shoemaker, J.M., 2001. Recycling process for carbon/epoxy composites, in: SAMPE 2001 Symposium \& Exhibition, SAMPE, Longbeach, CA, USA.

Alsop, S.H., 2009. Pyrolysis off-gas processing, in: SAMPE'09 Conference, SAMPE, Baltimore, MD, USA.

Astrom, B.T., 1997. Manufacturing of Polymer Composites. Chapman \& Hall, UK.

ATI, 1994. Adherent Technologies, Inc. Official website at www.adherenttech.com (last accessed July 2010) .

BIS, 2009. The UK Composites Strategy. Department for Business, Innovation \& Skills, available online at interactive.bis.gov.uk/advancedmanufacturing (last accessed July 2010) .

Blueseventy, 2010. Carbon race googles. Blueseventy, available online at www.blueseventy.com/products/detail/carbon_race, Blueseventy (last accessed July) . 
BMCI, 2010a. BMC 304 Data Sheet. Bulk Molding Componds Inc., available online at www.bulkmolding.com/datasheets/informational/BMC_304.pdf (last accessed July 2010) .

BMCI, 2010b. BMC 310 Data Sheet. Bulk Molding Componds Inc., available online at www.bulkmolding.com/datasheets/informational/BMC_310.pdf (last accessed July 2010) .

Borealis, 2009. Case study: BMW 7 Series dashboard carrier. Borealis Group, available online at www.borealisgroup.com/pdf/literature/borealis-borouge/ case-study/MY_CAST097_GB_2010_02_BB.pdf (last accessed July 2010) .

Buggy, M., Farragher, L., Madden, W., 1995. Recycling of composite materials. J. Mater. Process. Technol. 55, 448-456.

Carberry, W., 2008. Airplane Recycling Efforts Benefit Boeing Operators. Boeing AERO Magazine QRT 4.08, 6-13.

Carberry, W., 2009. Aerospace's role in the development of the recycled carbon fibre supply chain, in: Carbon Fibre Recycling and Reuse 2009 Conference, IntertechPira, Hamburg, Germany.

CFK, 2007. CFK Valley Stade Recycking GmbH \& Co. KG. Official website at www . cfk-recycling.com (last accessed July 2010) .

CFRRC, 2009. Carbon Fibre Recycling and Reuse Conference. Official website at www . cfrecycling. com (last accessed July 2010) .

Connor, M.L., 2008. Characterization of Recycled Carbon Fibers and Their Formation of Composites Using Injection Molding. Master Thesis. North Carolina State University, Raleigh, NC, USA.

Conroy, A., Halliwell, S., Reynolds, T., 2006. Composite recycling in the construction industry. Composites Part A 37, 1216-1222.

Cornacchia, G., Galvagno, S., Portofino, S., Caretto, F., Giovanni, Casciaro, Matera, D., Donatelli, A., Iovane, P., Martino, M., Civita, R., Coriana, S., 2009. Carbon fiber recovery from waste composites: an integrated approach for a commercially successful recycling operation, in: SAMPE'09 Conference, SAMPE, Baltimore, MD, USA.

Cunliffe, A.M., Jones, N., Williams, P.T., 2003. Pyrolysis of composite plastic waste. Environ. Technol. 24, 653-663.

Curry, R., 2010. Successful research programme allows high performance brake discs to be manufactured at lower cost. Press Release Log (January), 1-2. 
DeRosa, R., Telfeyan, E., Mayes, J.S., 2005. Current state of recycling sheet molding compounds and related materials. J. Thermoplast. Compos. Mater. 18, 219-240.

Eckert, C.A., Knutson, B.L., Debenedetti, P.G., 1996. Supercritical fluids as solvents for chemical and materials processing. Nature 383, 313-318.

ECRC, 2003. ECRC Services Company. Official website at www .ecrc-greenlabel .org (last accessed January 2010) .

Ellison, G.C., McNaught, R., 2000. The use of natural fibres in nonwoven structures for applications as automotive component substrates. Research \& Development Report NF0309. Ministry of Agriculture, Fisheries and Food, UK.

EU 1999/31/EC, 1999. Council Directive 1999/31/EC of 26 April 1999 on the landfill of waste. The Council of the European Union, Official Journal of the European Communities L 182-42, 1-19.

EU 2000/53/EC, 2000. Directive 2000/53/EC of the European Parliament and of the Council of 18 September 2000 on end-of-life vehicles. The Council of the European Union, Official Journal of the European Communities L 269-43, 34-42.

GCF, 2010. Green Carbon Fibre. Official website at www.greencarbonfibre.com (last accessed July 2010) .

George, P.E., 2009. End user perspective: Perspective on carbon fibre recycling from a major end user, in: Carbon Fibre Recycling and Reuse 2009 Conference, IntertechPira, Hamburg, Germany.

Giannadakis, K., Szpieg, M., Varna, J., 2010. Mechanical Performance of a Recycled Carbon Fibre/PP Composite. Exp. Mech. DOI: 10.1007/s11340-010-9369-8.

Gibson, R.F., 2010. A review of recent research on mechanics of multifunctional composite materials and structures. Compos. Struct. 92, 2793-2810.

Gosau, J.M., Wesley, T.F., Allred, R.E., 2009a. Carbon fiber reclamation from stateof-the-art 2nd generation aircraft composites, in: SAMPE'09 Conference, SAMPE, Baltimore, MD, USA.

Gosau, J.M., Wesley, T.F., Allred, R.E., 2009b. Recovering carbon fibre and more from scrap composite material, in: Carbon Fibre Recycling and Reuse 2009 Conference, IntertechPira, Hamburg, Germany.

Goto, M., 2009. Chemical recycling of plastics using sub- and supercritical fluids. J. Supercrit. Fluids 47, 500-507.

HADEG, 1995. HADEG Recycling GmbH. Official website at www . hadeg-recycling . de (last accessed July 2010) . 
Heil, J.P., Hall, M.J., Litzenberger, D.R., Clearfield, R., Cuomo, J.J., George, P.E., Carberry, W.L., 2009. A comparison of chemical, morphological and mechanical properties of various recycled carbon fibers, in: SAMPE'09 Conference, SAMPE, Baltimore, MD, USA.

Hitachi, 2010. Hitachi Chemical Co., Ltd. Official website at www.hitachi-chem.co.jp (last published July 2010) .

Howarth, J., Jeschke, M., 2009. Advanced non-woven materials from recycled carbon fibre, in: Carbon Fibre Recycling and Reuse 2009 Conference, IntertechPira, Hamburg, Germany.

Hunter, T., 2009. A recycler's perspective on recycling carbon fibre prepreg production scrap, in: Carbon Fibre Recycling and Reuse 2009 Conference, IntertechPira, Hamburg, Germany.

Hyde, J.R., Lester, E., Kingman, S., Pickering, S., Wong, K.H., 2006. Supercritical propanol, a possible route to composite carbon fibre recovery: A viability study. Composites Part A 37, 2171-2175.

Janicki, 2010. Janicki Industries, Inc. Official website at www.janicki.com (last accessed July 2010) .

Janney, M., Jr., E.G., Baitcher, N., 2007. Fabrication of Chopped Fiber Preforms by the 3-DEP Process, in: Composites and Polycon 2007, American Composites Manufactureres Association, Tampa, Florida, USA.

Janney, M.A., Newell, W.L., Geiger, E., Baitcher, N., Gunder, T., 2009. Manufacturing complex geometry composites with recycled carbon fiber, in: SAMPE'09 Conference, SAMPE, Baltimore, MD, USA.

JCMA, 2006. The Japan Carbon Fiber Manufacturers Association. Official website at www. carbonfiber.gr.jp (last accessed July 2010) .

Jiang, G., Pickering, S.J., Lester, E.H., Turner, T.A., Wong, K.H., Warrior, N.A., 2009. Characterisation of carbon fibres recycled from carbon fibre/epoxy resin composites using supercritical n-propanol. Compos. Sci. and Technol. 69, 192-198.

Jiang, G., Pickering, S.J., Walker, G.S., Bowering, N., Wong, K.H., Rudd, C.D., 2007. Soft ionisation analysis of evolved gas for oxidative decomposition of an epoxy resin/carbon fibre composite. Thermochim. Acta 454, 109-115.

Jiang, G., Pickering, S.J., Walker, G.S., Wong, K.H., Rudd, C.D., 2008. Surface characterisation of carbon fibre recycled using fluidised bed. Appl. Surf. Sci. 254, 2588-2593.

Jody, B.J., Pomykala, J.A., Daniels, E.J., Greminger, J.L., 2004. A process to recover carbon fibers from polymer-matrix composites in end-of-life vehicles. JOM 56, 43-47. 
Karborek, 1999. Karborek S.p.a. Official website at www.karborek.it/fibra (last accessed July 2010) .

Kennerley, J.R., Kelly, R.M., Fenwick, N.J., Pickering, S.J., Rudd, C.D., 1998. The characterisation and reuse of glass fibres recycled from scrap composites by the action of a fluidised bed process. Composites Part A 29, 839-845.

Kong, C., Bang, J., Sugiyama, Y., 2005. Structural investigation of composite wind turbine blade considering various load cases and fatigue life. Energy 30, 2101-2114.

Kouparitsas, C.E., Kartalis, C.N., Varelidis, P.C., Tsenoglou, C.J., Papaspyrides, C.D., 2002. Recycling of the fibrous fraction of reinforced thermoset composites. Polym. Compos. 23, 682-689.

Larsen, K., 2009. Recycling wind. Reinforced Plastics 53, 20-23,25.

Lester, E., Kingman, S., Wong, K.H., Rudd, C., Pickering, S., Hilal, N., 2004. Microwave heating as a means for carbon fibre recovery from polymer composites: a technical feasibility study. Mater. Res. Bull. 39, 1549-1556.

Lexus, 2009. Lexus LFA Press Information 2009. Toyota (GB) PLC - Lexus Division, available online at www.toyota.co.jp/en (last accessed July 2010) .

Line, S., 2009. Commercialisation of the carbon fibre recycling process, in: Carbon Fibre Recycling and Reuse 2009 Conference, IntertechPira, Hamburg, Germany.

Liu, Y.Y., Meng, L.H., Huang, Y.D., Du, J.J., 2004. Recycling of carbon/epoxy composites. J. Appl. Polym. Sci. 94, 1912-1916.

Liu, Y.Y., Shan, G.H., Meng, L.H., 2009. Recycling of carbon fibre reinforced composites using water in subcritical conditions. Mater. Sci. Eng., A 520, 179-183.

Marsh, G., 2005. Recycling collaborative combats legislation threat. Reinforced Plastics $49,24-28$.

Marsh, G., 2008. Reclaiming value from post-use carbon composite. Reinforced Plastics $52,36-39$.

Marsh, G., 2009. Carbon recycling: a soluble problem. Reinforced Plastics 53, 22-23, $25-27$.

McConnel, V.P., 2010. Launching the carbon fibre recycling industry. Reinforced Plastics 54, 33-37.

Menzolit, 2004a. Menzolit BMC 0400 Data Sheet. Available online at www.menzolit. com/templates/rhuk_solarflare_ii/pdf/list_bmc/BMC_0400.pdf, Menzolit GmbH. (last accessed July 2010) . 
Menzolit, 2004b. Menzolit BMC 1400 Data Sheet. Available online at www.menzolit. com/templates/rhuk_solarflare_ii/pdf/list_bmc/BMC_1400.pdf, Menzolit GmbH. (last accessed July 2010) .

Menzolit, 2008. Menzolit SMC 1800 Data Sheet. Available online at www.menzolit. com/templates/rhuk_solarflare_ii/pdf/list_smc/SMC_1800.pdf, Menzolit GmbH. (last accessed July 2010) .

Meredith, J., 2009. The role of recycled carbon fibre composites in motorsport applications, in: Carbon Fibre Recycling and Reuse 2009 Conference, IntertechPira, Hamburg, Germany.

Meyer, L.O., Schulte, K., Grove-Nielsen, E., 2007. Optimisation of a pyrolysis process for recycling of CFRP's, in: ICCM-16, Japan Society for Composite Materials, Kyoto, Japan.

Meyer, L.O., Schulte, K., Grove-Nielsen, E., 2009. CFRP-recycling following a pyrolysis route: Process optimization and potentials. J. Compos. Mater. 43, 1121-1132.

MIT, 2010. Materials Innovation Technologies, LLC. Official website at www . emergingmit.com (last accessed July 2010) .

Nakagawa, M., Shibata, K., Kuriya, H., 2009. Characterization of CFRP Using Recovered Carbon Fibers from Waste CFRP, in: Second International Symposium on Fiber Recycling, The Fiber Recycling 2009 Organizing Committee, Atlanta, Georgia, USA.

NASA, 1991. F-18 HARV in flight. Available online at www1.dfrc .nasa.gov/Gallery/ Photo/F-18HARV/Small/EC91-495-15.jpg (last accessed July 2010) .

Ogi, K., Nishikawa, T., Okano, Y., Taketa, I., 2007. Mechanical properties of ABS resin reinforced with recycled CFRP. Adv. Compos. Mater. 16, 181-194.

Palmer, J., Ghita, O.R., Savage, L., Evans, K.E., 2009. Successful closed-loop recycling of thermoset composites. Composites Part A 40, 490-498.

PAMELA, 2005. PAMELA Project. Official website at www.pamelalife.com (last accessed July 2010) .

PAMELA, 2008. PAMELA-Life: Main results of the project. Airbus S.A.S., available online at www.pamelalife.com/english/results/PAMELA-Life-project_ results-Nov08.pdf.

Panesar, S., 2009. Converting Composite Waste Into High Quality Reusable Carbon Fibre, in: JEC Composites Show, JEC Composites, Paris, France.

Pickering, S.J., 2006. Recycling technologies for thermoset composite materials current status. Composites Part A 37, 1206-1215. 
Pickering, S.J., 2009. Carbon fibre recycling technologies: what goes in and what comes out?, in: Carbon Fibre Recycling and Reuse 2009 Conference, IntertechPira, Hamburg, Germany.

Pickering, S.J., Kelly, R.M., Kennerley, J.R., Rudd, C.D., Fenwick, N.J., 2000. A fluidised-bed process for the recovery of glass fibres from scrap thermoset composites. Compos. Sci. Technol. 60, 509-523.

Pickering, S.J., Robinson, P., Pimenta, S., Pinho, S.T., 2010. Applications for recycled carbon fibre, in: meeting of the Increasing Sustainability and Recycling Consortium (10 June 2010), BIS — UK Composites Strategy, London, UK.

Pickering, S.J., Turner, T.A., Warrior, N.A., 2006. Moulding compound development using recycled carbon fibres, in: SAMPE Fall Technical Conference, SAMPE, Dallas, USA.

Pimenta, S., Pinho, S.T., Robinson, P., 2010b. Closing the loop: mechanical analysis and modelling of a multiscale recycled composite, in: ECCM-14, European Society of Composite Materials, Budapest, Hungary.

Pimenta, S., Pinho, S.T., Robinson, P., Wong, K.H., Pickering, S.J., 2010a. Mechanical analysis and toughening mechanisms of a multiphase recycled CFRP. Compos. Sci. Technol. 70, 1713-1725.

Pinero-Hernanz, R., Dodds, C., Hyde, J., Garcia-Serna, J., Poliakoff, M., Lester, E., Cocero, M.J., Kingman, S., Pickering, S., Wong, K.H., 2008a. Chemical recycling of carbon fibre reinforced composites in nearcritical and supercritical water. Composites Part A 39, 454-461.

Pinero-Hernanz, R., Garcia-Serna, J., Dodds, C., Hyde, J., Poliakoff, M., Cocero, M.J., Kingman, S., Pickering, S., Lester, E., 2008b. Chemical recycling of carbon fibre composites using alcohols under subcritical and supercritical conditions. J. Supercrit. Fluids 46, 83-92.

Quadrant, 2007. C100F23-F1 Product Data Sheet. Quadrant Plastic Composites Inc., available online at www.quadrantcomposites.com/files/cms1/DS_D100F23-F1. pdf (last accessed July 2010) .

Quadrant, 2010. Applications for Building and Construction. Quadrant Plastic Composites Inc., available online atwww.quadrantcomposites.com/English/page_14. aspx (last accessed July 2010) .

RCFL, 2009. Recycled Carbon Fibre Ltd. Official website at www. recycledcarbonfibre.com (last accessed July 2010) .

Roberts, A., 2007. Rapid growth forecast for carbon fibre market. Reinforced Plastics $51,10-13$. 
Roberts, A., 2009. The Carbon Fibre Industry Worldwide 2008-2014. Materials Technologies Publications, UK.

Sloan, J., 2008. Carbon Fiber 2007 looks forward with optimism. High Performance Composites Carbon Fiber 2007 Conference coverage, (Washington, DC, USA), Composites World, 5-7 December 2007.

Strong, A.B., Ploskonka, C.A., 1989. Fundamentals of Composites Manufacturing: materials, methods and applications. Society of Manufacturing Engineers, USA.

Szpieg, M., Wysocki, M., Asp, L.E., 2009a. Recycled polypropylene aimed as composites precursor material. Plast. Rubber Compos. 38, 412-418.

Szpieg, M., Wysocki, M., Asp, L.E., 2009b. Reuse of polymer materials and carbon fibres in novel engineering composite materials. Plast. Rubber Compos. 38, 419-425.

Takahashi, J., Matsutsuka, N., Okazumi, T., Uzawa, K., Ohsawa, I., Yamaguchi, K., Kitano, A., 2007. Mechanical properties of recycled CFRP by injection molding method, in: ICCM-16, Japan Society for Composite Materials, Kyoto, Japan.

Tarmac, 2010. Tarmac Aerosave S.A.S. Official website at www .tarmacaerosave.aero (last accessed July 2010) .

TFP, 2010. Technical Fibre Products Ltd. Official website at www.techfibres.com (last accessed July 2010) .

Turner, T.A., Pickering, S.J., Warrior, N.A., 2009. Development of high value composite materials using recycled carbon fibre, in: SAMPE'09 Conference, SAMPE, Baltimore, MD, USA.

Warrior, N.A., Turner, T.A., Pickering, S.J., 2009. AFRECAR and HIRECAR Project results, in: Carbon Fibre Recycling and Reuse 2009 Conference, IntertechPira, Hamburg, Germany.

Wong, K.H., Pickering, S.J., Brooks, R., 2007a. Recycled Carbon Fibre Reinforced Polypropylene Composites: Effect of Coupling Agents on Mechanical Properties, in: Composites Innovation 2007 - Improved Sustainability and Environmental Performance, NetComposites, Barcelona, Spain.

Wong, K.H., Pickering, S.J., Turner, T.A., Warrior, N.A., 2007b. Preliminary Feasibility Study of Reinforcing Potential of Recycled Carbon Fibre for Flame-retardant Grade Epoxy Composite, in: Composites Innovation 2007 - Improved Sustainability and Environmental Performance, NetComposites, Barcelona, Spain.

Wong, K.H., Pickering, S.J., Turner, T.A., Warrior, N.A., 2009a. Compression moulding of a recycled carbon fibre reinforced epoxy composite, in: SAMPE'09 Conference, SAMPE, Baltimore, MD, USA. 
Wong, K.H., Turner, T.A., Pickering, S.J., Warrior, N.A., 2009b. The Potential for Fibre Alignment in the Manufacture of Polymer Composites from Recycled Carbon Fibre, in: SAE AeroTech Congress and Exhibition, SAE International, Seattle, Washington, USA.

Wood, K., 2010. Carbon fiber reclamation: Going commercial. High-Performance Composites 3, 1-2.

Yip, H.L.H., Pickering, S.J., Rudd, C.D., 2002. Characterisation of carbon fibres recycled from scrap composites using fluidised bed process. Plast. Rubber Compos. 31, $278-282$. 